\title{
A Quantitative Measurement of the Dependence of Short-Term Synaptic Enhancement on Presynaptic Residual Calcium
}

\author{
K. R. Delaney ${ }^{1,2}$ and D. W. Tank ${ }^{1}$ \\ 'Biological Computation Research Department, AT\&T Bell Laboratories, Murray Hill, New Jersey 07974, and ${ }^{2}$ Department \\ of Physiology and Biophysics, New York University, New York, New York
}

We simultaneously measured presynaptic free calcium ion concentration $\left(\left[\mathrm{Ca}^{2}\right]_{i}\right)$ and synaptic strength at the crayfish claw opener neuromuscular junction ( $\mathrm{nmj}$ ) under a variety of experimental conditions. Our experiments were designed both to test the hypothesis that elevated $\left[\mathrm{Ca}^{2+}\right]_{i}$ is necessary and sufficient for the induction of a form of synaptic enhancement that persists for several seconds after tetanic stimulation-augmentation-and to determine the quantitative relationship between elevated $\left[\mathrm{Ca}^{2+}\right]_{i}$ and this enhancement.

Action potential trains increased $\left[\mathrm{Ca}^{2+}\right]_{i}$ and enhanced transmission. During the decay phase of synaptic enhancement known as augmentation (time constant of decay $\approx 7$ $\mathrm{sec}$ at $20^{\circ} \mathrm{C}$ with $<200 \mu \mathrm{m}$ fura-2 in terminals), $\left[\mathrm{Ca}^{2+}\right]_{i}$ was elevated $700 \mathrm{~nm}$ or less above rest and an essentially linear relationship between $\left[\mathrm{Ca}^{2+}\right]_{i}$ and enhancement was observed.

Introduction of exogenous $\mathrm{Ca}^{2+}$ buffers into the presynaptic terminal slowed the buildup and recovery kinetics of both $\left[\mathrm{Ca}^{2+}\right]_{i}$ and the component of synaptic enhancement corresponding to augmentation. The slope of the relationship relating $\Delta\left[\mathrm{Ca}^{2+}\right]_{i}$ to augmentation was not changed. The time course of augmentation and recovery of $\left[\mathrm{Ca}^{2+}\right]$, remained correlated as the temperature of the preparation was changed from about $10^{\circ} \mathrm{C}$ to $20^{\circ} \mathrm{C}$, but the quantitative relationship of enhancement to $\left[\mathrm{Ca}^{2+}\right]_{i}$ was increased more than two- to threefold.

During moderate frequency trains of action potentials, a slowly developing component of the total synaptic enhancement was approximately linearly related to residual $\left[\mathrm{Ca}^{2+}\right]_{\text {, }}$ measured with fura-2. The quantitative relationship between $\left[\mathrm{Ca}^{2+}\right]_{i}$ and this component of synaptic enhancement during trains was the same as that during synaptic augmentation after trains.

Bath application of the calcium ionophore A23187 increased $\left[\mathrm{Ca}^{2+}\right]_{i}$ and resulted in synaptic enhancement. The quantitative relationship between increased $\left[\mathrm{Ca}^{2+}\right]_{1}$ and synaptic enhancement was similar to that seen after augmentation-inducing action potential trains. Blocking $\mathrm{Na}^{+} / \mathrm{K}^{+}$pump

Received June 2, 1993; revised Feb. 11, 1994; accepted Feb. 24, 1994.

We thank Rodolfo Llinás and Robert Zucker for their encouragement and the benefit of numerous thoughtful discussions about transfer release and synaptic enhancement during the past few years. K.R.D. was supported by a Medical Research Council Canada postdoctoral award.

Correspondence should be addressed to Kerry Delaney, Department of Biological Sciences, Simon Fraser University, Burnaby, B.C. Canada V5T 1S6.

Copyright @ 1994 Society for Neuroscience $0270-6474 / 94 / 145885-18 \$ 05.00 / 0$ with ouabain also increased $\left[\mathrm{Ca}^{2+}\right]_{n}$ possibly through reversal or slowing of $\mathrm{Na}^{+} / \mathrm{Ca}^{2+}$ exchange. With increased $\left[\mathrm{Ca}^{2+}\right]_{i}$ of $300 \mathrm{~nm}$ or less above basal, the relationship between enhancement and $\left[\mathrm{Ca}^{2+}\right]$, produced by ouabain application was comparable to that seen during synaptic augmentation after a train.

Our results in conjunction with previous work (Delaney et al., 1989) support the hypothesis that elevated $\left[\mathrm{Ca}^{2+}\right]_{i}$ of about $1 \mu \mathrm{M}$ or less is a necessary and sufficient component for the production of augmentation and a longer-lasting form of activity-dependent synaptic enhancement, posttetanic potentiation (ptp). We conclude that the differing time constants of augmentation and ptp largely reflect multicomponent recovery kinetics of $\left[\mathrm{Ca}^{2+}\right]$, that occur following the stimulus conditions that produce these two forms of synaptic enhancement.

Our experiments also suggest that shorter-lasting facilitation of release, termed F1 and F2 facilitation, which decays within a second of the offset of stimulation, is not significantly activated by the increases in $\left[\mathrm{Ca}^{2+}\right]$, that are sufficient to produce augmentation and ptp. Evidence is presented

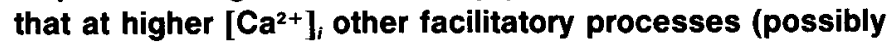
corresponding to $F 1$ or $F 2$ facilitation) contribute to the enhancement of both spontaneous and action potential-evoked release.

[Key words: augmentation, facilitation, posttetanic potentiation, crayfish neuromuscular junction, fura-2]

Activity-dependent or frequency-dependent synaptic enhancement is a fundamental property of a diversity of central and peripheral vertebrate and invertebrate synapses (Zengel et al., 1980; Atwood and Wojtowicz, 1986; Magleby, 1987; Atwood et al., 1989; Zucker 1989). It results from an increase in evoked and spontancous transmitter release that builds up during a train of presynaptic action potentials and decays following train termination. A calcium-based mechanism for activity-dependent synaptic enhancement has been popular since the initial experiments showing the necessity of extracellular calcium for transmitter release and for short-term facilitation to pairs of action potentials (Katz and Miledi, 1968). In this hypothesis, a persistent increase in intracellular $\left[\mathrm{Ca}^{2+}\right]_{i}$ produced by the action potential train is responsible for some or all forms of activitydependent synaptic enhancement and the recovery of $\left[\mathrm{Ca}^{2+}\right]_{\text {, }}$ back to basal levels determines the decay of synaptic enhancement.

A calcium hypothesis for synaptic enhancement is attractive for many reasons. It is now well established that each action 
potential during a train produces a transient calcium ion influx that evokes a transient release of transmitter seen as a postsynaptic or junctional potential. Calcium ions $\left(\mathrm{Ca}^{2+}\right)$ accumulate in the presynaptic terminal if they are not completely removed before the next action potential (Miledi and Parker, 1981; Charlton et al., 1982; Delaney et al., 1989, 1991; Tank et al., 1994), producing a longer-lasting increase in the concentration of free $\mathrm{Ca}^{2+}$ in the cytoplasm termed residual $\mathrm{Ca}^{2+}$. It is well established that elevation of free $\mathrm{Ca}^{2+}$ in presynaptic terminals enhances spontaneous and action potential-evoked release (e.g., Miledi, 1973; Erulkar and Rahamimoff, 1978; Charlton et al., 1982; Delaney and Zucker, 1990; Mulkey and Zucker, 1991). Therefore, in addition to the absolute requirement for $\mathrm{Ca}^{2+}$ influx for action potential-evoked release (Delaney and Zucker, 1990; Mulkey and Zucker, 1991; but see Hochner et al., 1989), $\mathrm{Ca}^{2+}$ "left over" from that required for evoked release could also be involved in some forms of synaptic enhancement (e.g., Katz. and Miledi, 1968; Erulkar and Rahamimoff, 1978; Connor et al., 1986; Augustine et al., 1987; Delaney et al., 1989). While it is clear that presynaptic free $\mathrm{Ca}^{2+}$ can modulate transmitter release, important questions remain regarding which types of activity-dependent synaptic enhancement are normally driven by residual $\mathrm{Ca}^{2+}$ and what is the quantitative relationship between residual $\mathrm{Ca}^{2+}$ and different forms of synaptic enhancement seen during and after trains of action potentials in presynaptic neurons. This information is especially useful in identifying the potential biochemical mechanisms that underlie enhancement.

Early models for $\mathrm{Ca}^{2+}$-mediated enhancement suggested that residual free $\mathrm{Ca}^{2+}$ summed with the transient $\mathrm{Ca}^{2+}$ flux produced by a subscquent action potential. In the classic "residual calcium model" (Katz and Miledi, 1968) a highly nonlinear relationship between $\left[\mathrm{Ca}^{2+}\right]$ and release is used to account for the observation that increased residual calcium produces a large enhancement of action potential-evoked release without causing a continuously high rate of spontaneous release. This model, while qualitatively able to account for the rapid decay of short-term facilitation, is unable to account quantitatively for many properties of the buildup and decay of synaptic enhancement (e.g., Zucker, 1974b; Zucker and Fogelson, 1986; Magleby, 1987). More recent modifications of the residual $\mathrm{Ca}^{2+}$ model for the shortestlasting phases of facilitation (persisting for $\approx 1 \mathrm{sec}$ or less) have suggested that the decay of this process is set by the reverse rate of a $\mathrm{Ca}^{2+}$-activated process such as the dissociation rate of $\mathrm{Ca}^{2+}$ from a facilitating site, rather than the decay of free $\mathrm{Ca}^{2+}$ in the cytoplasm (Balnave and Gage, 1974; Stanley, 1986; Robitaille and Charlton, 1991; Yamada and Zucker, 1992). Quantitative fluorimetric measurements of residual free calcium with fura-2 after prolonged high-frequency trains (Delaney et al., 1989) demonstrated that the classic residual calcium model is not appropriate to posttetanic potentiation (ptp), which persists many minutes after a train.

To date, the construction of a single unified model of $\mathrm{Ca}^{2+}$ mediated transmitter release and $\mathrm{Ca}^{2+}$-modulated synaptic enhancement has not been successfully achieved. Magleby and coworkers, in an extensive series of experiments at vertebrate neuromuscular junction ( $\mathrm{nmj}$ ), were unable to account for shortterm and longer-lasting forms of activity-dependent enhancement by a single mechanism (Magleby, 1987, for review). They proposed a scheme with separate facilitatory processes that act independently and multiplicatively to produce the total accumulated synaptic enhancement during and after trains of stim- uli. The existence of multiple independent facilitatory mechanisms, coupled with the inability to construct a single unified model of calcium-modulated enhancement, suggests there may be several independent $\mathrm{Ca}^{2+}$-modulated mechanisms for the different forms of synaptic enhancement. Quantitative studies of the relationship between cytoplasmic calcium concentration $\left(\left[\mathrm{Ca}^{2+}\right]_{i}\right)$ and enhancement are necessary to examine this hypothesis closely and distinguish different models.

We have previously demonstrated the feasibility of measuring presynaptic $\left[\mathrm{Ca}^{2+}\right]_{i}$ in individual nerve terminals during activity-dependent enhancement of synaptic transmission (Delaney et al., 1989, 1991; Regehr and Tank, 1991; Zucker et al., 1991; Regehr et al., 1994). The synaptic system we have studied here is the crayfish claw opener $\mathrm{nmj}$. This system was chosen because of (1) the profound frequency-dependent synaptic enhancement that it shows, (2) the absence or minimal contribution of synaptic depression compared to other model systems such as vertebrate nmj (Magleby, 1987) or squid giant synapse (Swandulla et al., 1991), and (3) the relative simplicity with which it is possible to simultaneously image individual presynaptic terminals and fluorimetrically determine $\left[\mathrm{Ca}^{2+}\right]_{i}$ while eliciting and recording postsynaptic excitatory junction potentials (ejp).

In the crayfish preparation, the recovery of synaptic enhancement after high-frequency trains, as well as its buildup during trains, is kinetically complex, requiring up to five time constants for a complete description (Atwood and Wojtowicz 1986; Atwood et al., 1989). During trains of action potentials $\left[\mathrm{Ca}^{2+}\right]_{i}$ rises in crayfish neuromuscular nerve terminals, eventually reaching a plateau when the rate of influx is equal to the rate of efflux (Tank et al., 1994). During trains of action potentials, accumulation of several components of synaptic enhancement occurs in a qualitatively similar fashion to the accumulation of $\mathrm{Ca}^{2+}$, reaching a plateau when the $\left[\mathrm{Ca}^{2+}\right]_{i}$ no longer increases or increasing slowly with slow increases in $\left[\mathrm{Ca}^{2+}\right]_{i}$ (Delaney et al., 1989, 1991).

Following the termination of a train of stimuli, the accumulated $\mathrm{Ca}^{2+}$ is removed and synaptic transmission strength returns to prestimulus levels. Two forms of enhancement termed F1 and F2 facilitation (Magleby, 1987) decay quickly and are absent within a few seconds. A longer-lasting component termed augmentation decays away more slowly with a time constant in the range of (5-7) sec. Much longer-lasting components of the decay are observed when the excitor axon is stimulated at higher frequencies, typically between $20 \mathrm{~Hz}$ and $30 \mathrm{~Hz}$ for longer periods (5-20 $\mathrm{min}$ ), so as to deliver several thousand action potentials to the presynaptic terminals. The component that decays with a time constant of several minutes is known as posttetanic potentiation (ptp). Trains of stimuli sufficient to produce ptp often result in production of another component described as long-term facilitation (LTF; Wojtowicz and Atwood, 1986) that persists for many hours or even days in intact animals, which does not appear to depend on persistently increased $\left[\mathrm{Ca}^{2+}\right]_{i}(\mathrm{De}-$ laney et al., 1989).

For the crayfish opener muscle preparation, we have previously shown that there is a temporal correlation between the recovery of $\left[\mathrm{Ca}^{2+}\right]_{i}$ in presynaptic terminals and synaptic enhancement during ptp (Delaney et al., 1989). We now show such a correlation exists between $\left[\mathrm{Ca}^{2+}\right]_{i}$ and augmentation, a shorterlasting synaptic enhancement that follows brief action potential trains, and have more accurately determined the mathematical form of the relationship. We have also performed experiments that strongly implicate increased presynaptic $\left[\mathrm{Ca}^{2+}\right]_{i}$ as a causal 
event in this form of synaptic enhancement; that is, increased $\left[\mathrm{Ca}^{2+}\right]_{i}$ is necessary and sufficient to induce augmentation and ptp. Because of technical limitations that make it difficult to measure rapidly changing $\left[\mathrm{Ca}^{2+}\right]_{i}$ selectively within a micrometer of the inner membrane surface, we are not primarily concerned in this study with short-term facilitation of release that decays within $1 \mathrm{sec}$ after a train, only the longer-lasting phases. Nonetheless, we have compared quantitatively the buildup of short-term facilitation (F1, F2 of Magleby, 1987) and augmentation to the buildup of residual $\left[\mathrm{Ca}^{2}\right]_{i}$ during trains of action potentials and these experiments provide insight into the potential role of residual $\mathrm{Ca}^{2+}$ in short-term facilitation. We conclude that elevated free $\left[\mathrm{Ca}^{2+}\right]_{i}$ is causal to the production of synaptic augmentation and ptp, but the $\left[\mathrm{Ca}^{2+}\right]_{i}$ we measure with fura-2 is not responsible for F1 and F2 facilitation. In general, our results narrow the possible biochemical/biophysical mechanisms that produce various forms of frequency-dependent synaptic facilitation and emphasize the need to consider the kinetic and quantitative aspects of $\mathrm{Ca}^{2+}$-activated processes in synaptic enhancement.

\section{Materials and Methods}

Microfluorimetric fura-2 measurement of presynaptic calcium. Crayfish were obtained from Waubun Labs (Shreveport, LA), maintained at $16^{\circ} \mathrm{C}$ and typically used within 1 month. Preparation of the crayfish opener muscle for simultaneous measurements of $\left[\mathrm{Ca}^{2+}\right]_{i}$ in presynaptic nerve terminals and ejps in muscle fibers has been described previously (Delaney et al., 1989, 1991). For experiments where $\left[\mathrm{Ca}^{2+}\right]_{i}$ and ejp amplitude were compared, the terminals chosen for imaging synapsed either on the same muscle fiber or on a fiber immediately adjacent to the one from which the ejp was recorded. The crayfish opener muscle is multiply innervated by the excitor axon with up to 50 terminals on each fiber, so the imaged terminals are only a subset of all the terminals producing the ejp. In order to acquire image pairs at about one per second (400 msec exposure per image plus readout time) with good signal to noise required injection of fura-2 to $100-200 \mu \mathrm{M}$ in terminals. Injection of this amount of fura- 2 slows the rate of recovery of $\left[\mathrm{Ca}^{2+}\right]_{i}$ $10-20 \%$ since it is a Ca ${ }^{2+}$ buffer (Tank et al., 1994). This effect of fura-2 on the rate of $\left[\mathrm{Ca}^{2+}\right]_{i}$ recovery means it is important for purposes of comparison to allow time for fura-2 to diffuse into all of the terminals on the muscle fiber from which an ejp is recorded and to measure the $\left[\mathrm{Ca}^{2+}\right]_{i}$ and ejp simultaneously.

The temperature of the preparation was measured with a $1-\mathrm{mm}$ diameter thermistor probe submerged in the saline beside the claw under the edge of the $40 \times$ immersion lens. During an experiment, temperature was controlled to within $\pm 1^{\circ} \mathrm{C}$ by a stage-mounted peltier device. Temperatures ranged from $10^{\circ} \mathrm{C}$ to $21^{\circ} \mathrm{C}$ for different experiments, as indicated in the text and figure legends.

Presynaptic terminals were filled by iontophoretic injection of the free acid form of fura-2 or the fluorescent $\mathrm{Na}^{+}$ion indicator SBFI (Minta and Tsien, 1989) into the axon of the excitor motor neuron. A Photometrics (Tuscon, AZ) CC200 cooled charge-coupled device camera attached to an upright microscope (Zeiss UEM) was used to acquire images of the $340 \pm 10 \mathrm{~nm}$ and $380 \pm 6.5 \mathrm{~nm}$ excited fluorescence from fura-filled presynaptic terminals from which ratiometric estimates of the intraterminal calcium concentration were made. Image acquisition, background subtraction, and ratio measurements were controlled by a Mac IIfx computer. The image acquisition and analysis system is described in greater detail by Regehr and Tank (1992). For calcium calibration, measurements of the $380 \mathrm{~nm}$ excitation intensity and 340: $380 \mathrm{~nm}$ ratios at saturated and zero calcium were obtained using 20$\mu$ m-pathlength cuvettes (Vitro Dynamics, Rockaway, NJ) as described previously (Delaney et al., 1989). We used a fura-2 dissociation constant $\left(K_{D}\right)$ of $865 \mathrm{~nm}$ in crayfish cytoplasm (see Delaney et al., 1989) and used Equation 5 of Grynkiewicz et al. (1985) with a viscosity correction factor of 0.7 to calculate calcium concentrations. We attempted to calibrate SBFI measurements of $\left[\mathrm{Na}^{+}\right]$by applying solutions in which the sum of $\mathrm{Na}^{+}$and $\mathrm{K}^{+}$were kept constant at $250 \mathrm{~mm}$ buffered with either 10 mM K$~_{+}^{+}$-HEPES or $\mathrm{Na}^{+}$-HEPES containing $0.1 \mathrm{mg} / \mathrm{ml} \mathrm{Na}^{+}$-monensin (thus, $0-\mathrm{Na}^{+}$solution contained approximately $0.14 \mathrm{mM} \mathrm{Na}^{+}$) and sat- urated gramicidin $(\approx 2 \mathrm{mg} / 25 \mathrm{ml})$ to SBFI-filled excitor axon to obtain fluorescence ratios at " 0 " $\mathrm{Na}^{+}$and "saturated" $\mathrm{Na}^{+}$. An arbitrary polynomial was fit to the data to obtain an estimate of the ratio at saturation and the $K_{D}$ estimated at $42 \mathrm{~mm}$ from the ratio at half-saturation. Estimates of $\left[\mathrm{Na}^{+}\right]$in nerve terminals were then calculated using Equation 5 of Grynkiewicz et al. (1985). Basal $\left[\mathrm{Na}^{+}\right]_{i}$ was thus estimated at approximately $17 \mathrm{~mm}$.

An important methodological consideration in all of our work comparing $\left[\mathrm{Ca}^{2+}\right]$, recovery rates to synaptic enhancement decay rates is that fura-2 calibration errors will not affect our basic results. The dissociation constant for fura in crayfish cytoplasm is estimated at about $850 \mathrm{nM}$, so for $\left[\mathrm{Ca}^{2+}\right]$ below about $1-2 \mu \mathrm{M}$ the value of $\left[\mathrm{Ca}^{2+}\right]$ calculated by application of Equation 5 of Grynkiewicz et al. (1985) is nearly linearly proportional to the ratio of the $340: 380 \mathrm{~nm}$ excited fluorescence. Therefore, the estimated time course of $\left[\mathrm{Ca}^{2+}\right]_{i}$ recovery during augmentation is not significantly affected by errors in estimating calibration parameters such as the ratio at zero and saturated $\mathrm{Ca}^{2+}$ or by the application of a viscosity correction factor (see Regehr and Tank, 1992, for detailed discussion). Quantitative estimates of the proportionality constant between $\left[\mathrm{Ca}^{2}\right]_{i}$ and enhancement or estimates of the calcium affinity of calcium-activated molecules will, however, be affected by such errors.

Terminals were viewed using a Zeiss $40 \times, 0.75$ NA water immersion lens. The terminals we imaged are approximately $3 \mu \mathrm{m}$ deep, so fluorescence contributions from the top and bottom of the terminal are essentially equal. Fura- 2 concentrations inside terminals were estimated from the intensity at $380 \mathrm{~nm}$ with pathlength estimated assuming a spherical cross section and $150 \mathrm{~nm}$ free calcium (see Tank et al., 1994, for details).

Electrophysiology, exogenous buffer injection, and calcium ionophores. Ejps were recorded from postsynaptic muscle fibers using standard intracellular recording techniques. Measurements of ejp amplitudes were made directly from Gould chart recordings of the amplifier output or from records that were digitized with a GW instruments A/D board (Cambridge, MA) and analyzed on a Mac IIfx computer using custom software. Linear and nonlinear least squares routines (implemented using commercial software, IGOR, Wavemetrics, Eugene, OR) were used to fit linear or exponential functions to data sets. Other data transformations including gaussian filtering and linear interpolation functions were implemented with this software as noted. Records of miniature excitatory junction potentials (mejps) were obtained by bandpass filtering intracellular recordings between 0.1 and $100 \mathrm{~Hz}$ with 100 $1000 \times$ total amplification and stored on FM tape for later playback to a chart recorder for analysis. Mejps were counted by eye from chart rccords and basclinc frequencics monitored in 5-10 min periods before treatments were between 0.5 and $2 \mathrm{~Hz}$. Shortly after high-frequency trains and when $\left[\mathrm{Ca}^{2+}\right]_{i}$ was high in ouabain, mejps frequently overlapped and occurrences were scored based on inflection points on the rising phase of records obtained at $125 \mathrm{~mm} / \mathrm{sec}$ chart speed.

We waited more than 1 sec after the end of an action potential train before comparing $\left[\mathrm{Ca}^{2+}\right]_{i}$ to synaptic strength. This is more than sufticient time for $\mathrm{Ca}^{2+}$ gradients present during the train to equilibrate within a structure the size of a crayfish neuromuscular terminal (e.g., Smith and Zucker, 1980).

There are differences in some properties of transmitter release from terminals innervating fibers on different parts of the opener muscle (Atwood and Wojtowicz, 1986). Unfacilitated ejps in proximal muscle fibers are larger and associated with higher release probabilities than ejps from fibers in the central portion of the muscle, but the amount of synaptic enhancement resulting from tetanic stimulation is greater in central fibers than in proximal fibers (Bittner and Segundo, 1989). Obvious differences in the buildup and recovery of $\left[\mathrm{Ca}^{2+}\right]_{i}$ between terminals on very proximal or central fibers, beyond those normally attributable to differences in surface area to volume, were not seen. Almost all results were obtained from terminals and muscle fibers that were intermediate between the central and the most proximal types. Unenhanced ejps were typically between 150 and $500 \mu \mathrm{V}$. These fibers show moderate to large synaptic enhancement with tetanic stimulation and do not exhibit signs of synaptic depression even with prolonged stimulation at $30 \mathrm{~Hz}$.

Coordination of image acquisition with stimulation and recording of ejps was controlled with a digital 8-channel stimulator (AMPI, Master8). Stimulus and imaging protocols relevant to various experiments are described in detail in the text or figure legends as appropriate. Since the timing of $\left[\mathrm{Ca}^{2+}\right]_{i}$ measurements and test ejps was never exactly coin- 
Table 1. Summary of linear regressions fitted to enhancement versus $\Delta\left[\mathrm{Ca}^{2+}\right]_{i}$

\begin{tabular}{|c|c|c|c|c|c|}
\hline Experiment & $\left({ }^{\circ} \mathrm{C}\right)$ & $r$ & $N$ & Intercept & $\begin{array}{l}\text { Enhance- } \\
\text { ment } \\
\left(\mu M^{-1}\right)\end{array}$ \\
\hline 1.8 .90 & (21) & 0.69 & 60 & 0.95 & 6.82 \\
\hline 1.31 .90 & (21) & 0.83 & 37 & 0.98 & 6.44 \\
\hline $5.29 .91^{a}$ & (21) & 0.98 & 17 & 0.88 & 14.1 \\
\hline $5.17 .91^{a}$ & (21) & 0.96 & 21 & 0.80 & 8.82 \\
\hline $5.16 .91^{a}$ & (21) & 0.97 & 21 & 0.97 & 5.83 \\
\hline $5.14 .91^{a}$ & (21) & 0.94 & 24 & 1.02 & 7.70 \\
\hline 3.10 .91 & (21) & 0.44 & 57 & 1.10 & 5.17 \\
\hline $2.16 .91^{b}$ & (20) & 0.68 & 188 & 0.91 & 5.01 \\
\hline 2.9 .91 & $(20)$ & 0.53 & 175 & 1.09 & 4.42 \\
\hline 3.5 .91 & (19) & 0.84 & 27 & 1.01 & 4.25 \\
\hline $8.28 .91^{b}$ & (19) & 0.84 & 92 & 1.11 & 5.63 \\
\hline $2.23 .91^{b}$ & $(18)$ & 0.86 & 79 & 0.98 & 3.16 \\
\hline $8.11 .91^{b}$ & $(18.5)$ & 0.80 & 86 & 1.01 & 6.96 \\
\hline $8.17 .91 \mathrm{a}^{b}$ & $(18.5)$ & 0.67 & 70 & 0.98 & 3.89 \\
\hline $8.17 .91 \mathbf{b}^{b}$ & (18.5) & 0.91 & 48 & 1.10 & 4.29 \\
\hline $8.20 .91^{b}$ & (18.5) & 0.86 & 99 & 1.03 & 4.73 \\
\hline $8.29 .91^{b}$ & (18.5) & 0.90 & 104 & 1.06 & 4.62 \\
\hline $8.30 .91^{b}$ & (18.5) & 0.76 & 35 & 1.12 & 3.25 \\
\hline $10.4 .91^{c}$ & $(16.5)$ & 0.86 & 73 & 0.93 & 3.79 \\
\hline $10.5 .91^{c}$ & $(16.5)$ & 0.59 & 69 & 0.87 & 2.33 \\
\hline $10.7 .91 \mathrm{a}^{\mathrm{c}}$ & $(16.5)$ & 0.76 & 70 & 1.02 & 3.54 \\
\hline $10.7 .91 b^{c}$ & $(16.5)$ & 0.82 & 74 & 0.96 & 4.21 \\
\hline $10.10 .91^{c}$ & $(16.5)$ & 0.63 & 110 & 1.19 & 3.21 \\
\hline $10.13 .91^{c}$ & $(16.5)$ & 0.83 & 198 & 0.95 & 3.61 \\
\hline \multicolumn{2}{|c|}{ Mean $\pm \mathrm{SD}$} & $0.79 \pm 0.14$ & & $1.00 \pm 0$. & \\
\hline
\end{tabular}

Enhancement is $\left(\mathrm{ejp}_{\mathrm{tcst}} / \mathrm{ejp}_{0}\right) / \Delta\left[\mathrm{Ca}^{2+}\right]_{i}$ in $\left.\mu \mathrm{M}\right)$. Intercept is enhancement at $\Delta\left[\mathrm{Ca}^{2+}\right]$ $=0 . N=$ number of points at which $\mathrm{Ca}$ and ejp were compared; $r=$ correlation coefficient. Note that mean $r$ is not weighted by number of points in each experiment. The average intercept $=1$, which indicates no enhancement in the absence of increased $\Delta\left[\mathrm{Ca}^{2+}\right]$, and provides further evidence for linearity of relationship. Data are not adjusted for possible effects of temperature on fura-2 dissociation (see text for discussion).

${ }^{\circ}$ In presence of $1 \mathrm{~mm}$ ouabain, for $\Delta\left[\mathrm{Ca}^{2+}\right]_{i}<0.4 \mu \mathrm{M}$.

${ }^{b}$ With injection of EDTA.

c After $4 \mathrm{sec}$ of $50 \mathrm{~Hz}$ stimulation.

cident, a linear interpolation algorithm was used to estimate the $\left[\mathrm{Ca}^{2+}\right]_{i}$ at the moment when each ejp was measured in order to compare ejp enhancement directly to $\left[\mathrm{Ca}^{2+}\right]_{i}$ (Table 1; Figs. $2 C, 4 C, 5 D, 6 C, 7 A, 8$ ). Stimulation at high frequencies results in contraction of the muscle fibers. Movement of the terminal between acquisition of the $340 \mathrm{~nm}$ and the $380 \mathrm{~nm}$ images of an image pair is the major difficulty in experiments that use high-frequency stimulation, but fortunately movement produces an easily recognized artifact and calcium concentrations were not determined for image pairs in which movement was detected.

Tank et al. (1994) modeled the slow (seconds to minutes) recovery of $\left[\mathrm{Ca}^{2+}\right]_{i}$ in nerve terminals following tetanic stimulation as a dynamic process reflecting unloading of cytoplasmic buffers and removal of $\mathrm{Ca}^{2+}$ via surface pumps. Consistent with a simple model, experiments demonstrated that increasing the total buffer capacity of the terminal by injection of large amounts of fura- 2 increased the time constant of $\left[\mathrm{Ca}^{2+}\right]$ recovery. Injection of kinetically fast buffers such as BAPTA or fura-2 to see if altered $\left[\mathrm{Ca}^{2+}\right]_{i}$ recovery kinetics alter the time course of augmentation was inappropriate for this study because they dramatically reduce evoked transmitter release at high concentrations. We therefore injected excess levels of EDTA to increase exogenous cytoplasmic $\mathrm{Ca}^{2+}$ buffering capacity since in cytoplasm it is a kinetically slower buffer and does not significantly reduce the amplitude of test ejps. EDTA was injected using 5-10 nA current applied for $60 \mathrm{~min}$ or more through pipettes containing approximately $200 \mathrm{~mm}$ EDTA, $150 \mathrm{~mm} \mathrm{KCl}$, and $10 \mathrm{~mm}$ fura-2. Injection was terminated when the fura- 2 concentrations were on the order of $200 \mu \mathrm{M}$ as indicated by the intensity of fluorescence. Successful injection of EDTA was determined when the rate of buildup of enhancement during tetanic stimulation was significantly slowed to between one-half and one-sixth as fast as with $200 \mu \mathrm{M}$ fura-2 alone. A very high concentration of fura- 2 was injected in experiments that measured the relationship between mejp frequency and $\left[\mathrm{Ca}^{2+}\right]_{i}$ following high-frequency trains. Injection of excess fura-2, by blocking the ejp, reduced movement artifacts normally caused by high-frequency stimulation, and thus permitted imaging of $\left[\mathrm{Ca}^{2+}\right]_{i}$ in the interval immediately after the offset of stimulation. In general, buffers were injected at one or two points in the axon and allowed to diffuse 1-2 hr before beginning experiments to ensure a uniform distribution of buffer in the terminals distributed over the fiber from which ejps or mejps were recorded.

The $\mathrm{Ca}^{2+}$ ionophore bromo-A23187 was used to raise presynaptic $\left[\mathrm{Ca}^{2+}\right]$, without electrical stimulation of the excitor axon. To prepare stock ionophore solution, $83 \mathrm{~mm}$ 4-bromo-A23187 in DMSO was diluted to $10-40 \mu \mathrm{M}$ in crayfish saline, vortexed $30 \mathrm{sec}$, and sonicated 5$10 \mathrm{~min}$. To compare the relationship of synaptic enhancement to elevation of $\left[\mathrm{Ca}^{2+}\right]_{i}$ by ionophore with that for augmentation and residual $\left[\mathrm{Ca}^{2+}\right]_{i}$ after trains, the following protocol was used. Prior to the addition of ionophore, the quantitative relationship between residual $\left[\mathrm{Ca}^{2+}\right]_{i}$ and synaptic enhancement during augmentation was determined using of $3-4 \mathrm{sec} 50 \mathrm{~Hz}$ trains followed by test stimuli at one per $1.5 \mathrm{sec}(0.67$ $\mathrm{Hz}$ ). By alternately beginning test stimuli $0.5 \mathrm{sec}$ or $1.5 \mathrm{sec}$ after the end of the train in several trials, it was possible to follow the decay of the ejp with $0.5 \mathrm{sec}$ resolution while stimulating at $0.67 \mathrm{~Hz}$. These short, high-frequency trains were used in order to acquire several augmentation trials for averaging; however, movement of the preparation immediately after the offset of the train usually resulted in the loss of the first one or two images after the train. Five to six minutes of $0.67 \mathrm{~Hz}$ stimulation was used to make control measurcments of cjp amplitude and $\left[\mathrm{Ca}^{2+}\right]_{i}$ in the same terminal and muscle fiber for which the $\left[\mathrm{Ca}^{2+}\right]_{i}$ versus augmentation relationship had been determined. At the end of the control period, the $40 \times$ water immersion lens was lifted out of the bath, and stock ionophore solution added to a final concentration of $0.5-4$ $\mu \mathrm{M}$. The solution bathing the preparation was then mixed manually by gentle trituration with a small pipette and the immersion lens replaced within about a minute. Two precautions were required to produce repeatable results. First, because $\mathrm{Br}-\mathrm{A} 23187$ has limited solubility in saline, vigorous sonication for more than $5 \mathrm{~min}$ was required to create a fine suspension of DMSO-ionophore micelles. Second, pilot experiments indicated that $\left[\mathrm{Ca}^{2+}\right]_{i}$ increases occurred more slowly in terminals on the underside of muscle fibers that were part of a bundle in the proximal portion of the muscle than in terminals on the surface. We therefore imaged terminals on, and recorded from, muscle fibers located near the transition between the proximal and central regions since these were often somewhat separated from adjacent fibers, improving access of the ionophore to the terminals on both sides of the fiber. When ionophore or ouabain was used to elevate $\left[\mathrm{Ca}^{2+}\right]_{i}, 100 \mu \mathrm{M}$ picrotoxin was added to the bath to block the potential effects of spontaneous GABA release from the inhibitory terminal.

Fura-2 pentapotassium salt, 4-bromo A23187, and the sodium-sensitive indicator SBFI were obtained from Molecular Probes (Eugene, OR). Ouabain, monensin, gramicidin, and picrotoxin were obtained from Sigma.

\section{Results}

\section{Comparison of calcium in presynaptic terminals with synaptic enhancement}

In the first part of this study we measured the $\left[\mathrm{Ca}^{2+}\right]_{i}$ in crayfish presynaptic terminals during the decay phase of synaptic augmentation. We filled presynaptic terminals of the excitor axon of the walking leg claw opener muscle with fura-2 and used the ratio method with a high-resolution $C C D$ camera to measure $\mathrm{Ca}^{2+}$ ion concentration. Synaptic enhancement was produced by trains of action potentials in the excitor axon elicited by stimulation of a branch of the leg nerve. Synaptic strength was measured from the amplitude of ejps recorded using microelectrodes in muscle fibers postsynaptic to imaged terminals. In all figures, synaptic enhancement is defined as the amplitude of test ejps after the train, divided by the average ejp amplitude during 
1-2 min before the train. Thus, control levels are equivalent to an enhancement of 1 , and an enhancement of 3 indicates the amount of transmitter released by the test ejp is three times that of the control. By the convention of Magleby (1987), and others, enhancement is thus equivalent to $(1+$ augmentation $)$ in the absence of facilitation or ptp.

A low-magnification fluorescence image of an excitor axon injected with fura- 2 is shown in Figure $1 A$. Injection of fura-2 fills large sections of the axonal arbor and hundreds of individual presynaptic terminals are available for imaging. Most measurements of $\left[\mathrm{Ca}^{2+}\right]_{i}$ were made from 3-8- $\mu$ m-diameter terminal boutons. Considerable differences in the rate of accumulation and recovery of $\left[\mathrm{Ca}^{2+}\right]_{i}$ are seen between bouton-like terminals and axonal regions with comparable diameters; dynamics of calcium accumulation and recovery are typically faster in terminals than in axon. In some but not all instances this can be attributed to differences in surface area-to-volume ratios. $\mathrm{Re}$ gardless of the reason for this difference, it means that for comparison with electrophysiological measurements we only consider $\left[\mathrm{Ca}^{2+}\right]_{i}$ in terminal boutons, not axon.

We waited 1-2 sec after the end of the stimulus trains before examining the relationship between recovery of $\left[\mathrm{Ca}^{2+}\right]_{i}$ and persistence of synaptic enhancement. This allowed for the complete decay of the shortest-term components of facilitation (F1 and F2), and provided time for the steep spatial gradients of calcium that exist immediately after an action potential to dissipate. A quantitative comparison between the decay of the ejp enhancement and the recovery of $\left[\mathrm{Ca}^{2+}\right]_{i}$ was then possible. Stimulus trains of sufficient duration and frequency to produce augmentation, but little or no ptp, were used (Atwood and Wojtowicz, 1986).

Ejps were recorded intracellularly from muscle fibers at the same time as measurements of the $\left[\mathrm{Ca}^{2+}\right]_{i}$ dynamics were made in terminals. After brief high-frequency, or longer moderatefrequency trains of action potentials, evoked synaptic transmitter release is enhanced for several seconds. Beginning 1-2 sec after a train, the decay of synaptic enhancement is well fit by a single exponential with approximately the same time constant as that for recovery of $\left[\mathrm{Ca}^{2+}\right]_{i}$ to resting levels (Fig. 1B). Thus, elevated $\left[\mathrm{Ca}^{2+}\right]_{i}$ and synaptic enhancement decay in parallel during the period normally ascribed to synaptic augmentation (Magleby, 1987). This is illustrated by the semilogarithmic plot of Figure $1 B$ following a $4 \mathrm{sec} 50 \mathrm{~Hz}$ train. The decay of $\left[\mathrm{Ca}^{2+}\right]_{i}$ and enhancement following a variety of moderate stimulus trains, for example, $8-20 \mathrm{~Hz}$ for $30-120 \mathrm{sec}$ or $50 \mathrm{~Hz}$ for $2-4 \mathrm{sec}$ is similar to that shown in Figure $1 B$.

A close correspondence between $\left[\mathrm{Ca}^{2+}\right]_{i}$ recovery and the duration of synaptic enhancement was seen in all experiments. This central result - that the recovery of $\left[\mathrm{Ca}^{2+}\right]_{i}$ and the decay of synaptic enhancement during the period associated with augmentation occur with a very similar time course-was observed in all of our experiments. Since $\left[\mathrm{Ca}^{2+}\right]_{i}$ and enhancement recover at the same rate, plotting ejp enhancement versus $\Delta\left[\mathrm{Ca}^{2+}\right]_{i}$ reveals a linear relationship (e.g., Figs. $2 C, 4 C, 5 D$ ). A summary of the lines obtained from many experiments after fitting to a linear function is contained in Table 1. The slope of these plots can be used to compare quantitatively the relationship between $\Delta\left[\mathrm{Ca}^{2+}\right]_{i}$ and augmentation under different conditions and between preparations. The calculated ordinate intercept is 1 , indicating no enhancement as $\left[\mathrm{Ca}^{2+}\right]_{i}$ returns to pretrain levels as expected if the data were well fit by a linear function. Across all experiments, the slope of the relationship varies from 2.33
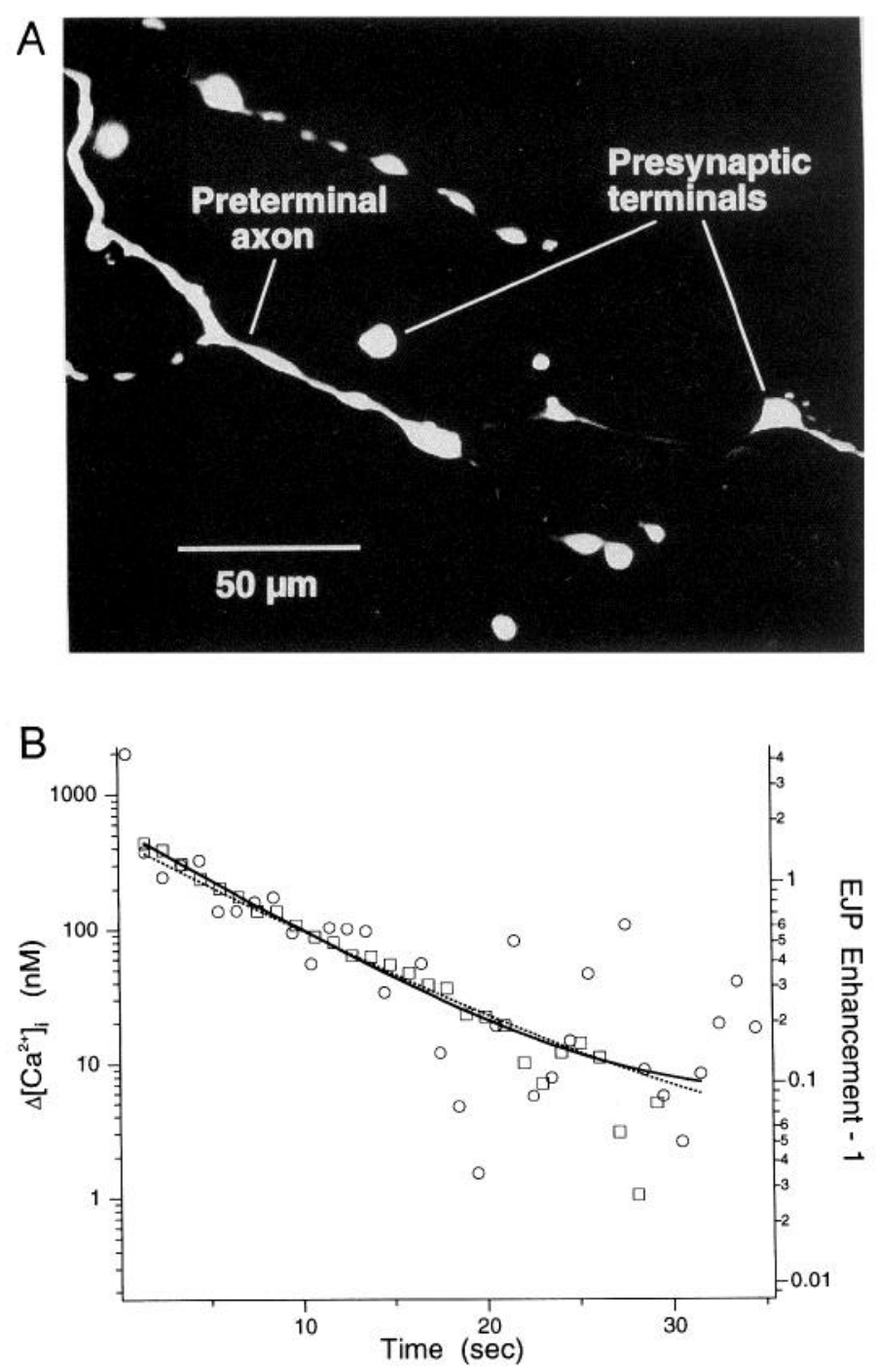

Figure 1. A, Fluorescence image of fura-2-filled terminals $(380 \mathrm{~nm}$ excitation). Image shows preterminal axon, en passant terminals, and synaptic boutons at the end of thin axonal processes located on the surface of two adjacent muscle fibers. Fura- 2 was injected into the main axonal trunk at a site about $1 \mathrm{~mm}$ away from this field of view. $B$, Semilogarithmic plot of synaptic enhancement and elevation in basal $\left[\mathrm{Ca}^{2+}\right]_{i}$ versus time during the $30 \mathrm{sec}$ following a $4 \mathrm{sec} 50 \mathrm{~Hz}$ train of action potentials. Squares are $\Delta\left[\mathrm{Ca}^{2+}\right]$ with the first image taken approximately $1.5 \mathrm{sec}$ after the train; circles are ejp amplitude, average of nine trials. Solid line is exponential fit to ejp data and dashed line is exponential fit to $\Delta\left[\mathrm{Ca}^{2+}\right]_{i}$ data, both beginning about $1.5 \mathrm{sec}$ after train, that is, starting with the second ejp test stimulus to allow for decay of short-term facilitation. The slight curvature in the fitted lines reflects the fact that fits were not constrained to zero at $t=\infty$. $\tau$ recovery $\Delta\left[\mathrm{Ca}^{2+}\right]_{i}=9.3 \mathrm{sec} ; \tau$ decay enhancement $=8.4 \mathrm{sec} ; T=16.5^{\circ} \mathrm{C}$.

to $14.1 \mu \mathrm{M}^{-1} \mathrm{Ca}^{2+}$. Some of this variation may reflect differences between the amount of augmentation expressed by terminals on different fibers similar to that which is observed for facilitation (Bittner and Segundo, 1989). In addition, a strong effect of temperature on the relationship between $\Delta\left[\mathrm{Ca}^{2+}\right]_{i}$ and enhancement is observed that contributes to this large range (see below, Fig. 5).

\section{Is synaptic augmentation caused by elevation of $\left[\mathrm{Ca}^{2+}\right]_{\mathrm{i}}$ ?}

In the next part of this study we attempted to dissociate the recovery of $\left[\mathrm{Ca}^{2+}\right]$, from augmentation to test the hypothesis 

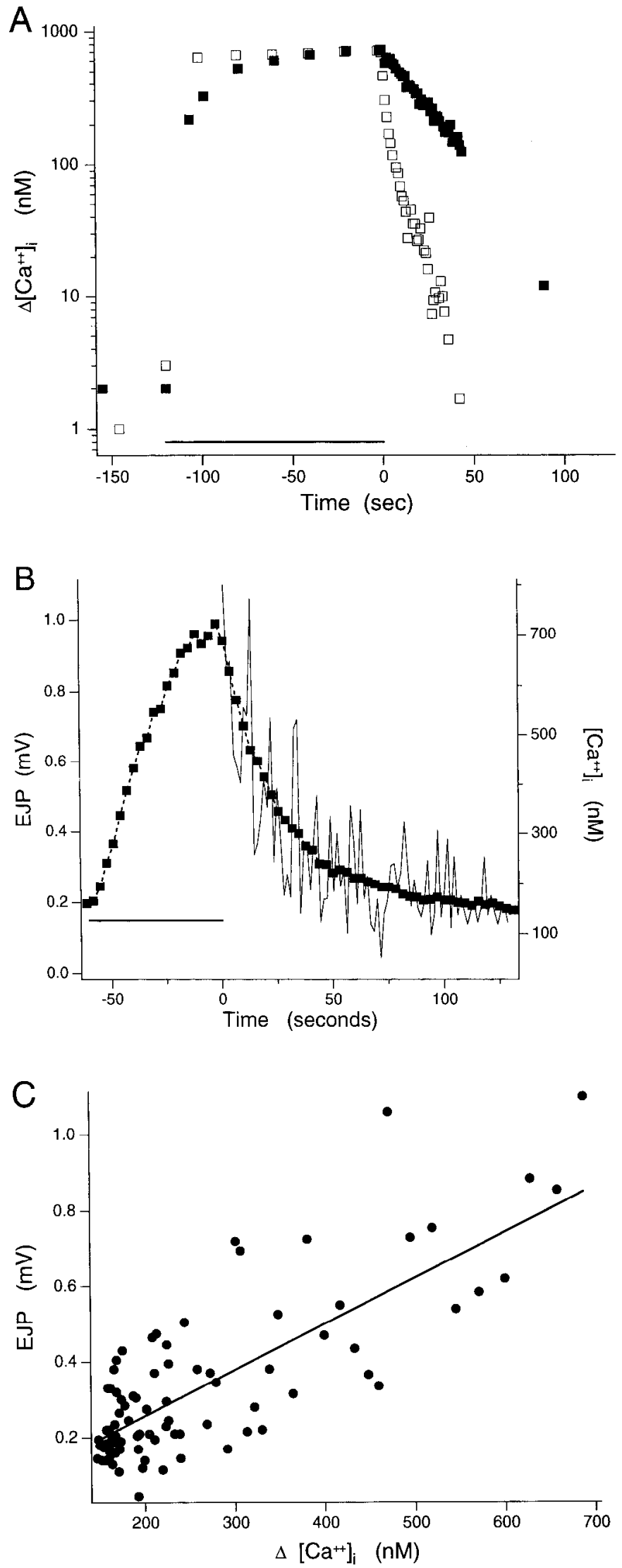

Figure 2. A, Effect of increasing cytoplasmic $\mathrm{Ca}^{2+}$ buffer capacity on recovery of calcium accumulations. Open squares. buildup and recovery of $\left[\mathrm{Ca}^{2+}\right]_{i}$ with $120 \mathrm{sec}$ stimulation at $15.2 \mathrm{~Hz}$ with fura- 2 concentration of about $200 \mu \mathrm{M}$. Iontophoretic injection of EDTA into the axon to

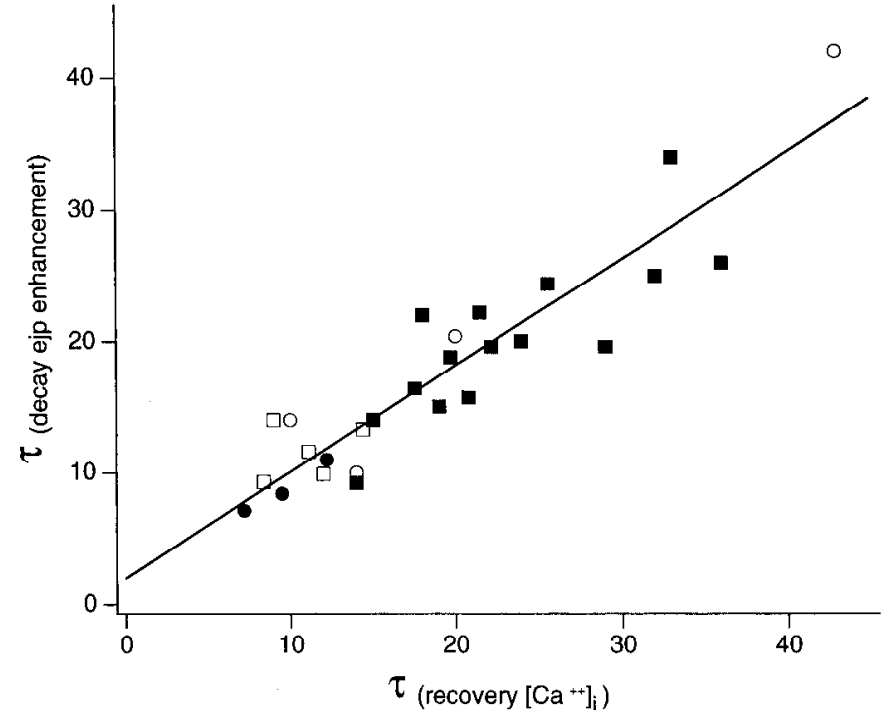

Figure 3. Comparison of rate of decay of synaptic enhancement to rate of recovery of presynaptic $\left[\mathrm{Ca}^{2+}\right]_{i}$ after trains of stimuli. Time constants (in seconds) were estimated using an exponential fitting function beginning 1.5-3 sec after offset of stimulation. Solid squares, decay rates after 60 or $120 \mathrm{sec}$ of $15.2 \mathrm{~Hz}$ stimulation in preparations injected with EDTA at $18.5-20^{\circ} \mathrm{C}$; open squares, recovery following $2-4 \mathrm{sec}$ of $50 \mathrm{~Hz}$ stimulation at $16.5^{\circ} \mathrm{C}$; open circles, $30 \mathrm{sec}, 15.2 \mathrm{~Hz}$, at $12.5^{\circ} \mathrm{C}$, $15.5^{\circ} \mathrm{C}$, or $17^{\circ} \mathrm{C}$; solid circles, same preparations with temperature 20 $21^{\circ} \mathrm{C}$ (one preparation at $17^{\circ} \mathrm{C}$ does not have corresponding point at $20^{\circ} \mathrm{C}$ ). Solid line is linear fit to data, slope $=0.81, r=0.91$, intercept $=1.96$.

that synaptic augmentation is causally related to elevated basal $\left[\mathrm{Ca}^{2+}\right]_{i}$ in presynaptic terminals. The logic of the experiments that follow is that if augmentation is causally related to residual $\left[\mathrm{Ca}^{2+}\right]_{i}$, then altering the kinetics of $\left[\mathrm{Ca}^{2+}\right]_{i}$ recovery should produce quantitatively and kinetically similar effects on synaptic strength. $\mathrm{Ca}^{2+}$ recovery kinetics were manipulated by (1) increasing the $\mathrm{Ca}^{2+}$ buffering capacity of presynaptic terminals through injection of exogenous $\mathrm{Ca}^{2+}$ buffer, and (2) slowing the rate of $\mathrm{Ca}^{2+}$ removal following trains of action potentials by cooling. In other experiments we attempted to determine the contribution of elevated $\left[\mathrm{Ca}^{2+}\right]_{i}$ to augmentation and short-term F1/F2 facilitation during trains by comparing the buildup of $\left[\mathrm{Ca}^{2+}\right]_{i}$ to the buildup of synaptic enhancement during stimulation.

In other experiments, we elevated $\left[\mathrm{Ca}^{2+}\right]_{i}$ directly using a $\mathrm{Ca}^{2+}$ ionophore, or indirectly via inhibition of $\mathrm{Na}^{+} / \mathrm{K}^{+}$pumps, in the absence of action potential trains to test whether the magnitude of increased $\left[\mathrm{Ca}^{2+}\right]_{i}$ present after trains is alone sufficient

increase $\mathrm{Ca}^{2+}$ buffer capacity results in slowing of both the rate of buildup as well as the rate of recovery of $\left[\mathrm{Ca}^{2+}\right]$, as shown by the solid squares. $B$, In another preparation, injection of EDTA slows the rate of recovery of the cjp (solid line) and the rate of recovery of $\left[\mathrm{Ca}^{2+}\right]_{i}$, (solid squares, connected by dashed line), after a $15.2 \mathrm{~Hz}$ train to the same extent; $\tau$ ejp decay, $24 \mathrm{sec} ; \tau$ recovery $\left[\mathrm{Ca}^{2+}\right]_{i}, 26 \mathrm{sec}$. The solid line is an average of three trials with the ejp tested every $1.5 \mathrm{sec}$, starting 0.5 sec after the train. The time constant of ejp decay was approximately $6 \mathrm{sec}$ before fura-2 and EDTA injection. Ejp and $\left[\mathrm{Ca}^{2+}\right]_{i}$ scaled to their respective maximum and minimum values between approximately 2 $\mathrm{sec}$ and $125 \mathrm{sec}$ after the train. $C$, Plot of ejp amplitude versus presynaptic $\left[\mathrm{Ca}^{2+}\right]_{i}$ illustrates the roughly linear relationship between these two variables starting $1.5 \mathrm{sec}$ after a $15.2 \mathrm{~Hz}$ train. Straight line is a linear least-squares fit. 
to account for the amount of augmentation. The slope of the relationship between $\left[\mathrm{Ca}^{2+}\right]_{i}$ and synaptic enhancement produced with ionophore or ouabain was comparcd to that observed in response to elevated $\left[\mathrm{Ca}^{2+}\right]_{i}$ after trains of action potentials before addition of ionophore, or in other experiments under similar conditions without addition of ouabain.

\section{Effects of injection of calcium buffers on residual $\left[\mathrm{Ca}^{2+}\right]_{\mathrm{i}}$ and synaptic enhancement}

Figure $2 A$ shows the effect of EDTA-increased intraterminal buffer capacity on the buildup and recovery of $\left[\mathrm{Ca}^{2+}\right]_{i}$. The injected buffer slowed both the rate of buildup of $\left[\mathrm{Ca}^{2+}\right]_{i}$ during trains and its recovery after trains. The $\left[\mathrm{Ca}^{2+}\right]_{i}$ at the plateau level is comparable after addition of excess buffer despite the slowing of the buildup. The similar plateau level suggests that addition of EDTA does not significantly affect the influx of $\mathrm{Ca}^{2+}$ per action potential or the rate of $\mathrm{Ca}^{2+}$ removal by surface pumps (see Tank et al., 1994). In the experiment shown in Figure $2 A$, injection of EDTA slows the recovery for timcs beginning $2 \mathrm{sec}$ after the train from approximately 8 to $24 \mathrm{sec}$. Identical results were obtained with injection of EGTA but this buffer produced greater reduction of the unenhanced ejp relative to its slowing $\left[\mathrm{Ca}^{2+}\right]_{i}$ recovery so they are not reported here.

Comparison of the time course of enhancement to the recovery of cytoplasmic $\left[\mathrm{Ca}^{2+}\right]_{i}$ after a train of action potentials indicates that both processes are slowed to the same extent by EDTA-increased buffer capacity. In the experiment shown in Figure $2 B$, the time constant for recovery of $\left[\mathrm{Ca}^{2+}\right]_{i}$ was $26 \mathrm{sec}$ and for ejp enhancement the time constant was $24 \mathrm{sec}$. Before injection of EDTA, the time constant for recovery of ejp enhancement was about $7 \mathrm{sec}$ in the same preparation (in this experiment the time constant of $\left[\mathrm{Ca}^{2+}\right]_{i}$ recovery could not be measured before addition of EDTA because EDTA and fura were coinjected). A close correspondence between the rate of recovery of $\left[\mathrm{Ca}^{3+}\right]_{i}$ and decay of synaptic enhancement after injection of EDTA was observed in nine of nine experiments across a wide range of buffer concentrations (solid squares in Fig. 3; see also Table 1 experiments indicated by $b$ ). Figure 3 summarizes the correspondence between recovery rates of $\left[\mathrm{Ca}^{2+}\right]_{i}$ and ejp enhancement under various conditions: high and low exogenous $\mathrm{Ca}^{2+}$ buffer, with different stimulus frequencies and durations and at high and low temperature. The strong correspondence between rate of recovery of $\left[\mathrm{Ca}^{2+}\right]_{i}$ and decay of augmentation provides evidence for the necessity of free $\mathrm{Ca}^{2+}$ for the activation and maintenance of the synaptic augmentation process, that is, that calcium dynamics is the rate-limiting step in augmentation.

Although increasing buffer capacity slows the rate of recovery of $\left[\mathrm{Ca}^{2+}\right]_{i}$ and the decay of augmentation after a train, it does not appreciably change the relationship between $\left[\mathrm{Ca}^{2+}\right]_{i}$ and enhancement (mean \pm SD enhancement, no buffer, no ouabain: $5.42 \pm 1.17 \mu \mathrm{M}^{-1}, 19-21^{\circ} \mathrm{C}, n=5$; with EDTA: $4.80 \pm 1.13$ $\mu \mathrm{M}^{-1}, 18.5-20^{\circ} \mathrm{C}, n=8$; values from Table 1 - note slightly lower temperatures for EDTA experiments).

\section{Buildup of residual $\left[\mathrm{Ca}^{2 !}\right]_{\mathrm{i}}$ and synaptic enhancement during trains of action potentials}

With moderate-frequency trains, synaptic enhancement and residual $\left[\mathrm{Ca}^{2+}\right]_{i}$ normally build up and plateau within $15 \mathrm{sec}$. We first examine whether some part of the total synaptic enhancement seen during moderate frequency trains is correlated with temporally and spatially averaged residual $\left[\mathrm{Ca}^{2+}\right]_{i}$ measured by fura-2. We then ask whether the relationship between a component of synaptic enhancement and the residual $\left[\mathrm{Ca}^{2+}\right]_{i}$ measured during a train of action potentials is quantitatively similar to that seen between residual $\left[\mathrm{Ca}^{2+}\right]_{i}$ and augmentation after a train.

The normally rapid rise of synaptic enhancement and $\Delta\left[\mathrm{Ca}^{2+}\right]_{i}$ during $15.2 \mathrm{~Hz}$ trains makes it difficult to compare the two processes. Injection of EDTA slows the buildup of residual $\left[\mathrm{Ca}^{2+}\right]_{i}$ during trains, making it possible to better compare the buildup of $\left[\mathrm{Ca}^{2+}\right]_{i}$ to ejp amplitude during trains by separating the early rapid phase(s) of synaptic enhancement from the later slowly increasing phase. During the first few seconds after the start of stimulation an initially rapid increase in ejp amplitude is seen with little increase in fura-2 measured $\left[\mathrm{Ca}^{2+}\right]_{i}$ (Fig. $4 A$ ). Then, with maintained stimulation the ejp amplitude continues to increase slowly during the train. To be consistent with other figures, enhancement and $\left[\mathrm{Ca}^{2+}\right]_{i}$ are presented scaled to their respective maxima and minima. Scaled in this way, there is a clear mismatch between the change in $\left[\mathrm{Ca}^{2+}\right]_{i}$ and the ejp enhancement that is particularly pronounced at the beginning of the train. Comparison of enhancement to $\Delta\left[\mathrm{Ca}^{2+}\right]_{i}$ after the train again reveals the linear relationship between augmentation and $\left[\mathrm{Ca}^{2+}\right]_{i}$ (Fig. $4 B ; C$, circles). This comparison also indicates that later during the train (Fig. $4 C$, dots) a slow buildup of enhancement is linearly correlated with a buildup of $\left[\mathrm{Ca}^{2+}\right]_{i}$. The portion of synaptic enhancement linearly related to $\Delta\left[\mathrm{Ca}^{2+}\right]_{i}$ during the train appears offset by processes that reach a maximum shortly after the onset of stimulation (Fig. 4C) and the relationship between enhancement and $\Delta\left[\mathrm{Ca}^{2+}\right]_{i}$ is steeper than after the train. From these data, we asked whether an augmentation-like process is proportional to residual free $\left[\mathrm{Ca}^{2+}\right]_{i}$ occurring during the train, and what appears to be the relationship between facilitation and augmentation during the train.

From Figure $4 A$ it can be seen that with injection of EDTA, much of the initial synaptic enhancement occurs in the first second or two after the onset of stimulation, in the absence of large increases in residual free $\mathrm{Ca}^{2+}$. During a $15.2 \mathrm{~Hz}$ train, short-term facilitation (F1 and F2) is expected to accumulate rapidly and comprise a significant portion of the total synaptic enhancement. Assuming facilitation builds up rapidly and then remains constant while augmentation continues to increase as $\left[\mathrm{Ca}^{2+}\right]_{i}$ increases, we found, as previously suggested by Magleby (1987), that a multiplicative rather than additive interaction between facilitation and augmentation was better able to account for the total synaptic enhancement.

In the convention of Magleby (1987),

$$
\text { release }=R_{0} \cdot(1+F) \cdot(1+A) \cdot(1+P),
$$

where $R_{0}=$ release in the absence of synaptic enhancement, $F$ $=$ effect of short-term facilitation $\mathrm{F} 1$ and F2, $A=$ augmentation, and $P=$ ptp. For our moderate-frequency, relatively brief trains we assume ptp is absent. By our convention enhancement $=$ release $/ R_{0}$, so in the absence of facilitation $(F)$, enhancement $=$ $(1+A)$. In Figure $4 B$ we apply a linear regression to the data for enhancement versus $\Delta\left[\mathrm{Ca}^{2+}\right]_{i}$ after the train to obtain an estimate of $(1+A)$. We did not have a direct measure of steadystate facilitation in the absence of augmentation. Enhancement 1-2 sec after the onset of the train was approximately $3.5(1+$ $F$ ), suggesting steady-state facilitation $F=2.5$. However $\Delta\left[\mathrm{Ca}^{2+}\right]_{i}$ at this time is $30-55 \mathrm{~nm}$, so some augmentation is expected to contribute to this enhancement and $F$ should be $<2.5$. We used a value of 2.1 for steady-state facilitation, and in the absence 

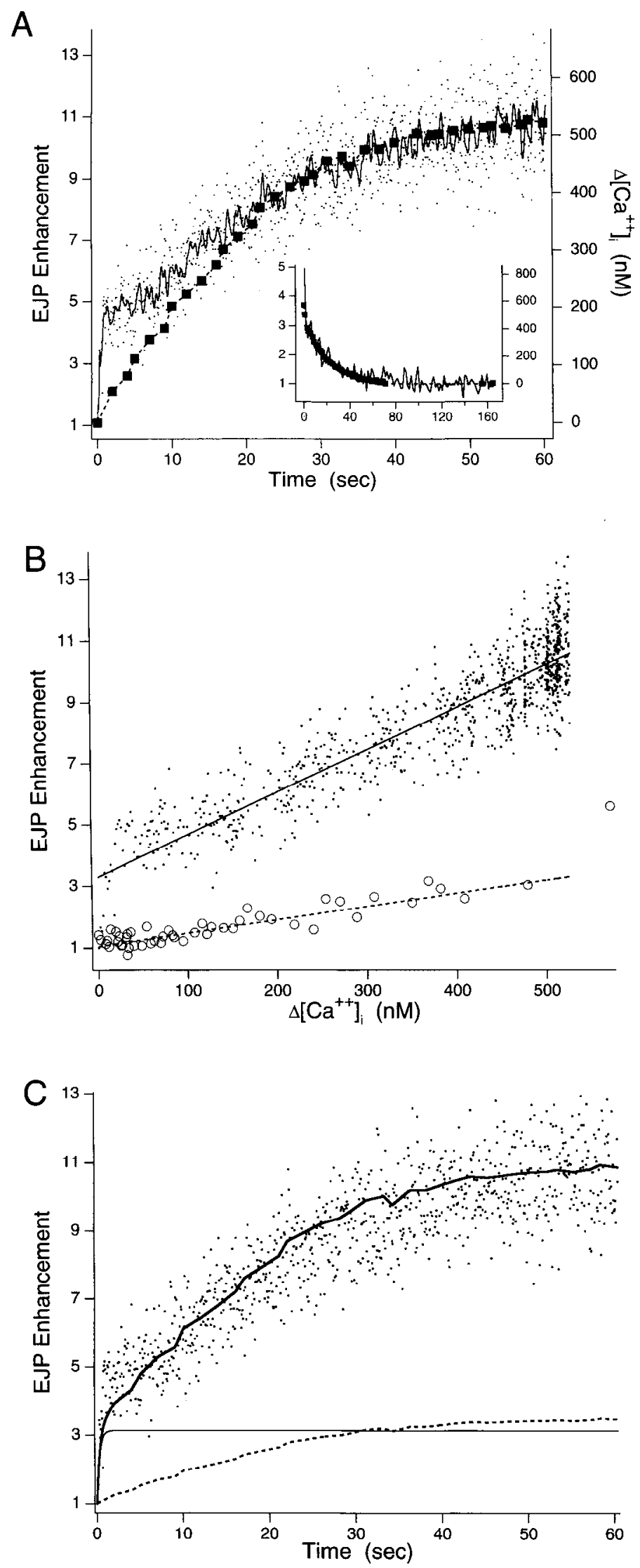

Figure 4. A, Buildup of $\left[\mathrm{Ca}^{2+}\right]_{t}$ (solid squares) and synaptic enhancement (dots; solid line is the result of applying a gaussian filter to smooth the data) during $15.2 \mathrm{~Hz}$ train. Axon was injected with EDTA to slow the rate of buildup and recovery of $\Delta\left[\mathrm{Ca}^{\gamma+}\right]_{i}$. Inset, Comparison betwecn recovery of residual calcium (solid squares with dashed line connecting of a more well-defined model, an exponential function using the characteristic decay rates of $F 1$ and $F 2$ phases of facilitation to estimate the buildup of $F$. Details of the method by which we obtaincd the modeled and fitted lines in Figure 4 arc containcd in the legend. Empirically, this provided a reasonable fit for the multiplicative model, both initially when enhancement is dominated by facilitation and later during the train, when facilitation and augmentation contribute to the total enhancement. Results like those illustrated in Figure 4 were observed in five of five experiments. In four of these experiments, an additive model clearly underestimated the observed total enhancement during a train, whereas a multiplicative adjustment produced a match between the slow phase of enhancement and $\left[\mathrm{Ca}^{2+}\right]_{i}$ during trains. In the remaining experiment, the total enhancement at the end of the train was about four times basal, so a difference between an additive and multiplicative adjustment was not readily apparent. These results suggest that the slowly increasing phase of enhancement during $15 \mathrm{~Hz}$ trains is produced by the slowly building residual $\mathrm{Ca}^{2+}$ and is due to the same $\mathrm{Ca}^{2+}$-driven process as augmentation after trains (Fig. $4 C$, inset).

\section{Temperature-dependent changes in residual calcium and synaptic enhancement}

Lowering the temperature increases the accumulation of $\mathrm{Ca}^{2+}$ during trains and slows the rate of recovery after trains. Cooling broadens the action potential contributing to the increased accumulation. Cooling probably also slows $\mathrm{Ca}^{2+}$ pumping, which will increase accumulation and slow the recovery of $\Delta\left[\mathrm{Ca}^{2+}\right]_{i}$ after trains.

Despite these multiple effects of cooling on $\mathrm{Ca}^{2+}$ handling

points) and synaptic enhancement after stimulation at $15.2 \mathrm{~Hz}$ for 60 sec (solid line, average of three trials; axes are the same as main graph). $B$, Total synaptic enhancement versus $\Delta\left[\mathrm{Ca}^{2+}\right]_{i}$ during a $15.2 \mathrm{~Hz}$ train (dots with fitted linear regression as solid line) and after the train (open circles with a fitted linear regression shown as dashed line). Synaptic enhancement is plotted directly against $\Delta\left[\mathrm{Ca}^{2+}\right]_{i}$ following application of a linear interpolation algorithm to $\Delta\left[\mathrm{Ca}^{2+}\right]$, data to calculate $\Delta\left[\mathrm{Ca}^{2+}\right]_{\text {i }}$ at times corresponding to measurements of synaptic enhancement. For data after the train, the point farthest to the right, at $\Delta\left[\mathrm{Ca}^{2+}\right]_{i}=575$ $\mathrm{nM}$, was obtained $0.5 \mathrm{sec}$ after the train, before the full decay of shortterm facilitation. This point is presented to show that when facilitation is present the synaptic enhancement is greater than expected based on the measured $\Delta\left[\mathrm{Ca}^{2+}\right]_{i}$ but it is not included in the calculation of the best-fitted line. The straight line through the data obtained during the train was fit between $\Delta \mathrm{Ca}=75 \mathrm{nM}$ and $525 \mathrm{nM}$, that is, between 5 and $60 \mathrm{sec}$ after the start of the train when short-term facilitation is expected to have plateaued. A component of the total enhancement during the train appears linearly related to $\Delta\left[\mathrm{Ca}^{2+}\right]_{i}$. C, EJP enhancement during the train can be modeled (thick solid curve through dots) as the product of estimated short-term facilitation $(1+F$; thin solid line $)$ and predicted augmentation $(1+A$; dashed line $)$; that is, enhancement $=(1+F) \cdot(1$ $+A$ ). The predicted augmentation during the train is based on the relationship observed between augmentation and $\Delta\left[\mathrm{Ca}^{2+}\right]_{i}$ after the train (dashed line in $B$ ). The estimate for facilitation was derived assuming facilitation builds up exponentially during the train with two time constants of 0.03 and $0.3 \mathrm{sec}$, respectively (e.g., Magleby, 1987). For simplicity we assumed the contribution of each component to the total facilitation was equal. The steady state facilitation $(1+F)$ was estimated to be 3.1 by dividing the total synaptic enhancement at $t=60 \mathrm{sec}$ by 3.4 , which is the augmentation $(1+A)$ predicted to be present during the train at $t=60 \mathrm{sec}$ (dashed line). This estimated value for $1+F$ is similar to the observed value for enhancement shortly after the start of the train when the contribution of augmentation is small. An additive model (enhancement $=1+A+F$ ) requires $F$ to be approximately 7 in order to match the total enhancement at the end of the train, and this grossly overestimates enhancement at early times. 

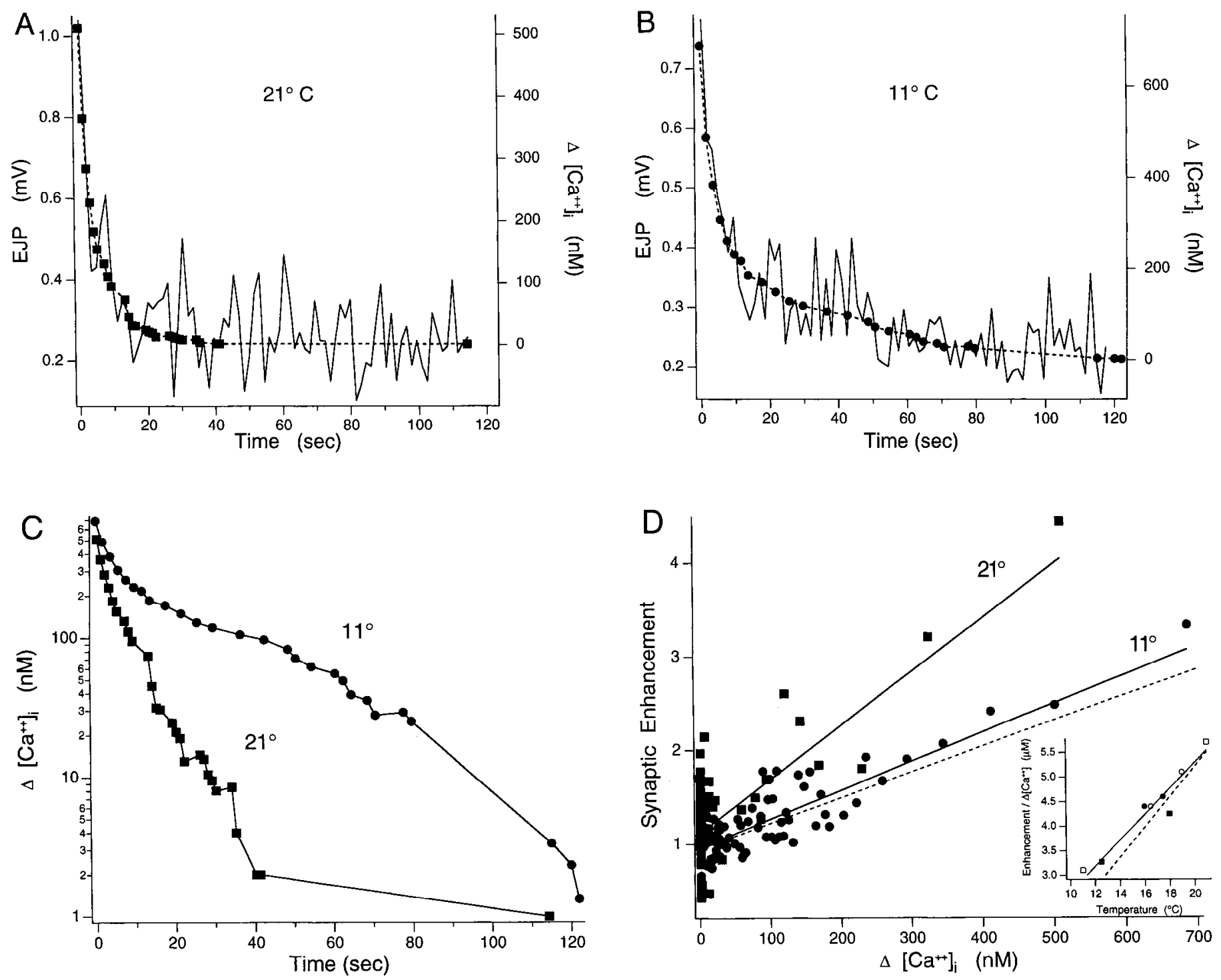

Figure 5. Effect of lowering temperature on relationship between residual $\left[\mathrm{Ca}^{2+}\right]_{i}$ and synaptic enhancement. $A$ and $B$, Recovery of synaptic enhancement (solid line) and $\left[\mathrm{Ca}^{2+}\right]_{i}$ (solid symbols, dashed line) at $21^{\circ} \mathrm{C}(A)$ and $11^{\circ} \mathrm{C}(B)$. $C$, Semilogarithmic plot of data from $A$ and $B$ highlights the period of nonexponential recovery of $\left[\mathrm{Ca}^{2+}\right]$, after a $30 \mathrm{sec} 15.2 \mathrm{~Hz}$ train at low temperature. $D$, Direct comparison of synaptic enhancement to residual $\left[\mathrm{Ca}^{2+}\right]_{i}$ following trains at $21^{\circ} \mathrm{C}$ and $11^{\circ} \mathrm{C}$. Lines are linear regression fits to data. Dashed line shows effect of adjusting $\left[\mathrm{Ca}^{2+}\right]_{i}$ estimates at $11^{\circ} \mathrm{C}$ for a possible $15 \%$ increase in $K_{D}$ for fura-2 associated with a $10^{\circ} \mathrm{C}$ temperature decrease. Inset, Change in slope of relationship between $\left[\mathrm{Ca}^{2+}\right]_{i}$ and augmentation in four preparations tested at both low and high temperature; different symbols represent different preparations. Solid line is least-squares regression to data, slope $=0.26 /{ }^{\circ} \mathrm{C}$, without temperature adjustment of $K_{D}$. Dashed line shows effect of adjusting the fitted line for possible temperature-dependent change in $K_{D}$ fura- 2 of $15 \% / 10^{\circ} \mathrm{C}$, slope $=0.30 /{ }^{\circ} \mathrm{C}$.

in the terminals, cooling slowed the decay of synaptic enhancement to the same extent as the recovery of $\left[\mathrm{Ca}^{2+}\right]_{i}$ (Fig. 5). Above $12^{\circ} \mathrm{C}$, the decay of synaptic enhancement and the recovery of $\left[\mathrm{Ca}^{2+}\right]_{i}$ were adequately described by a single exponential starting $2 \mathrm{sec}$ after a train. However, when the preparation was cooled below about $12^{\circ} \mathrm{C}$, the recovery of $\left[\mathrm{Ca}^{2+}\right]_{i}$ after the train was often markedly nonexponential. Even after only moderate-frequency stimulation $(15.2 \mathrm{~Hz}$ for $60 \mathrm{sec}$; Fig. $5 B)$ the recovery of $\left[\mathrm{Ca}^{2+}\right]_{i}$ often exhibited a pronounced "hump" at around 100$200 \mathrm{~nm}$ above rest at these low temperatures. Fitting such data with a single exponential is not appropriate, so these experiments are not included in the summary of time constants in Figure 3. However, it is still possible to compare synaptic enhancement directly to residual $\left[\mathrm{Ca}^{2+}\right]_{i}$ (e.g., Fig. $5 D$ ) and this comparison revealed that despite a distinctly nonexponential recovery of residual $\left[\mathrm{Ca}^{2+}\right]_{i}$ at low temperatures, synaptic enhancement and residual $\left[\mathrm{Ca}^{2+}\right]_{i}$ are strongly correlated. In four preparations, we determined the relationship between augmentation and residual $\left[\mathrm{Ca}^{2+}\right]_{i}$ at two temperatures in the same fiber and terminals. The relationship was consistently less steep at lower temperatures, showing an approximately twofold reduction with a $10^{\circ} \mathrm{C}$ temperature drop (Fig. $5 D$, inset). In the absence of direct measurements of the effect of temperature on fura-2 dissociation constant wc dccided to leave estimates of $\left[\mathrm{Ca}^{2+}\right]_{i}$ unadjusted for temperature in Table 1. Reducing temperature from $20^{\circ} \mathrm{C}$ to $10^{\circ} \mathrm{C}$ increases the dissociation constant of BAPTA about 15\% (Harrison and Bers, 1987). If the temperature sensitivity of $K_{D}$ of fura-2 is similar to $K_{D}$ of BAPTA, adjusting estimates of $\left[\mathrm{Ca}^{2+}\right]_{i}$ by $15 \%$ per $10^{\circ} \mathrm{C}$ would increase the apparent sensitivity of augmentation to $\left[\mathrm{Ca}^{2+}\right]_{i}$. 

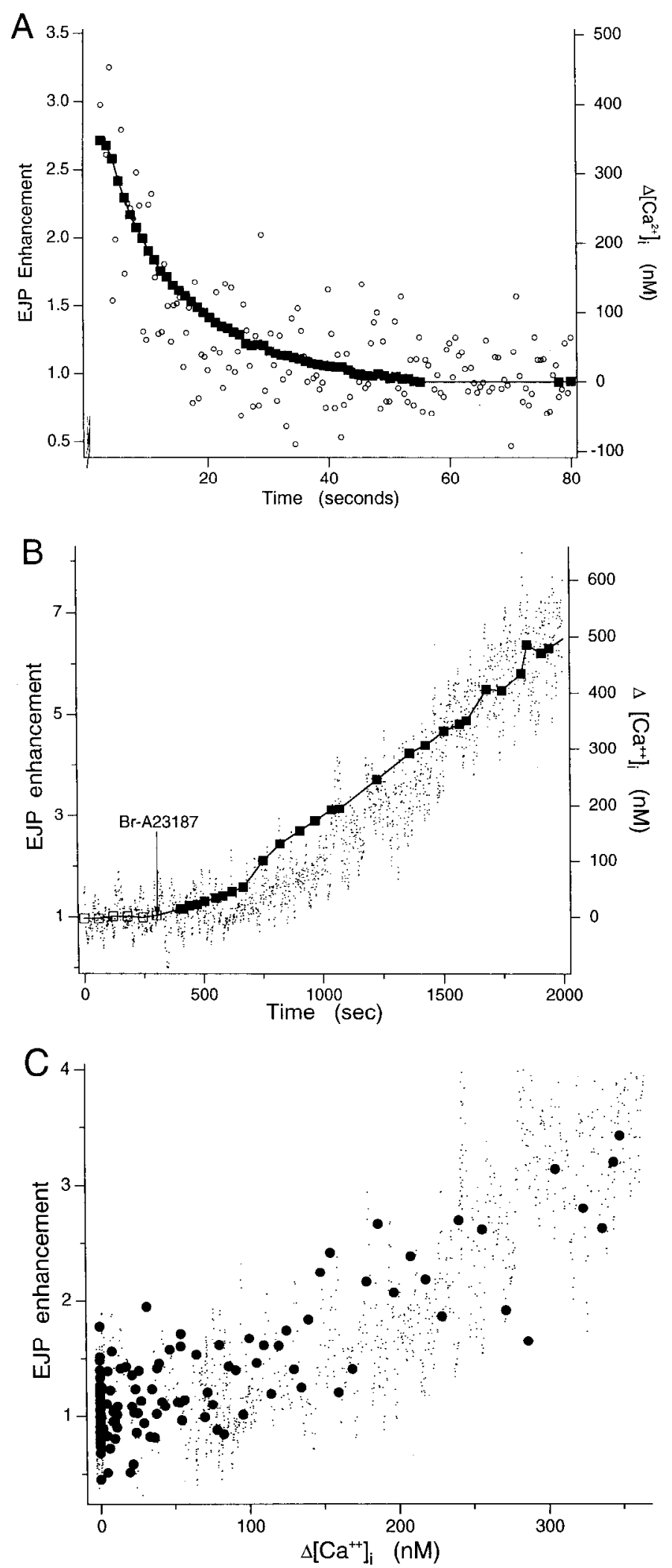

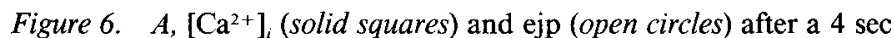
$50 \mathrm{~Hz}$ train. Data for ejps are averages of five trials with $1 \mathrm{~Hz}$ stimulation beginning $0.5 \mathrm{sec}$ after the train and five trials beginning $1 \mathrm{sec}$ after the train (details in Materials and Methods). $B,\left[\mathrm{Ca}^{2+}\right]_{i}$ and ejp before and during application of $\mathrm{Ca}^{2+}$ ionophore $0.5 \mu \mathrm{M}$ bromo-A23187. Ionophore was added at arrow, as indicated. Open squares, $\left[\mathrm{Ca}^{2+}\right]_{i}$ before ionophore; solid squares, $\left[\mathrm{Ca}^{2+}\right]_{t}$ in presence of ionophore. Dots show enhancement defined as ejp amplitude divided by average ejp amplitude during the $5 \mathrm{~min}$ before ionophore addition. $C$, Comparison of synaptic

\section{Effects of increasing residual $\left[\mathrm{Ca}^{2+}\right]_{\mathrm{i}}$ without trains of action potentials}

Although considerable evidence indicates that increased basal $\left[\mathrm{Ca}^{2+}\right]_{i}$ results in enhancement of action potential evoked transmitter release (Charlton et al., 1982; Delaney and Zucker, 1990; Hochner et al., 1990; Mulkey and Zucker, 1991; Swandulla et al., 1991), the question rcmains as to whether the residual $\left[\mathrm{Ca}^{3+}\right]_{i}$ reaches levels that are by themselves sufficient to account for observed synaptic enhancement or does residual calcium act synergistically with some other factor such as $\left[\mathrm{Na}^{+}\right]_{i}$ or presynaptic membrane potential (Bittner and Baxter, 1989) to produce augmentation. Data presented so far indicate that following a train of action potentials, the time course of synaptic augmentation follows the time course of elevated basal $\left[\mathrm{Ca}^{2+}\right]_{i}$ even under conditions of altered $\left[\mathrm{Ca}^{2+}\right]_{i}$ recovery kinetics. However, since the elevation of $\left[\mathrm{Ca}^{2+}\right]_{i}$ was produced by trains of action potentials, it is possible that prior tetanic stimulation combined with increased basal $\left[\mathrm{Ca}^{2+}\right]_{i}$ is required to produce enhanced release. Perhaps the transiently high $\left[\mathrm{Ca}^{2+}\right]_{i}$, near the membrane surface, produced by each action potential "sensitizes" the release apparatus so that after the train relatively moderate increases in residual $\left[\mathrm{Ca}^{2+}\right]_{i}$ produce significant synaptic enhancement.

Increased $\left[\mathrm{Ca}^{2+}\right]_{i}$ produced by application of $\mathrm{Ca}^{2+}$ ionophore was accompanied by an approximately parallel increase in ejp amplitude (Fig. 6B). The data presented in Figure 6 were obtained from a fiber that was somewhat separated from other fibers in the proximal/central boundary region and is representative of three other preparations with similarly favorable geometry. The relationship between $\left[\mathrm{Ca}^{2}{ }^{+}\right]_{i}$ and augmentation before ionophore treatment (Fig. 6A) is remarkably similar to that during treatment (Fig. $6 \mathrm{~B}$ ) over a range of $\left[\mathrm{Ca}^{2+}\right]_{i}$ from at least 0 to $350 \mathrm{~nm}$ above rest (Fig. $6 \mathrm{C}$ ). Thus, the magnitude of the increased $\left[\mathrm{Ca}^{2+}\right]_{i}$ after a moderate intensity action potential train is sufficient to account quantitatively for the amount of synaptic enhancement seen during augmentation, and "sensitization" of the release process to the effects of elevated $\left[\mathrm{Ca}^{2+}\right]_{i}$ is not required to account for augmentation.

The slight delay between the increase in the ejp and the increase in $\left[\mathrm{Ca}^{2+}\right]_{i}$ in the first 5-10 min after addition of ionophore probably reflects faster access of ionophore to terminals on the upper surface of muscle fibers. The terminals used to calculate the relationship between $\left[\mathrm{Ca}^{2+}\right]_{i}$ and synaptic enhancement in Figure 6 were on the surface of the fiber so the $\left[\mathrm{Ca}^{2+}\right]_{i}$ reported will tend to overestimate slightly the average $\left[\mathrm{Ca}^{2+}\right]_{i}$ in all terminals on the fiber and thus slightly underestimate the relationship between ionophore induced $\left[\mathrm{Ca}^{2+}\right]_{i}$ increases and enhancement, especially at first, before ionophore has penetrated to the underside of the fiber or to terminals buried in folds in the muscle surface. Later, when $\left[\mathrm{Ca}^{2+}\right]_{i}$ in terminals on the sur-

enhancement to ionophore and tetanus-induced changes in $\left[\mathrm{Ca}^{2+}\right]_{i}$. Solid circles show synaptic enhancement versus residual $\left[\mathrm{Ca}^{2+}\right]_{i}$ during synaptic augmentation after $4 \sec 50 \mathrm{~Hz}$ trains (data from $A$ ). Dots show relationship for synaptic enhancement versus $\left[\mathrm{Ca}^{2+}\right]_{i}$ observed with application of ionophore (data from $B$ ). When $\left[\mathrm{Ca}^{2+}\right]_{i}$ is raised using an ionophore, the amount of enhancement produced is comparable to that observed during augmentation after a short high-frequency train of action potentials. 

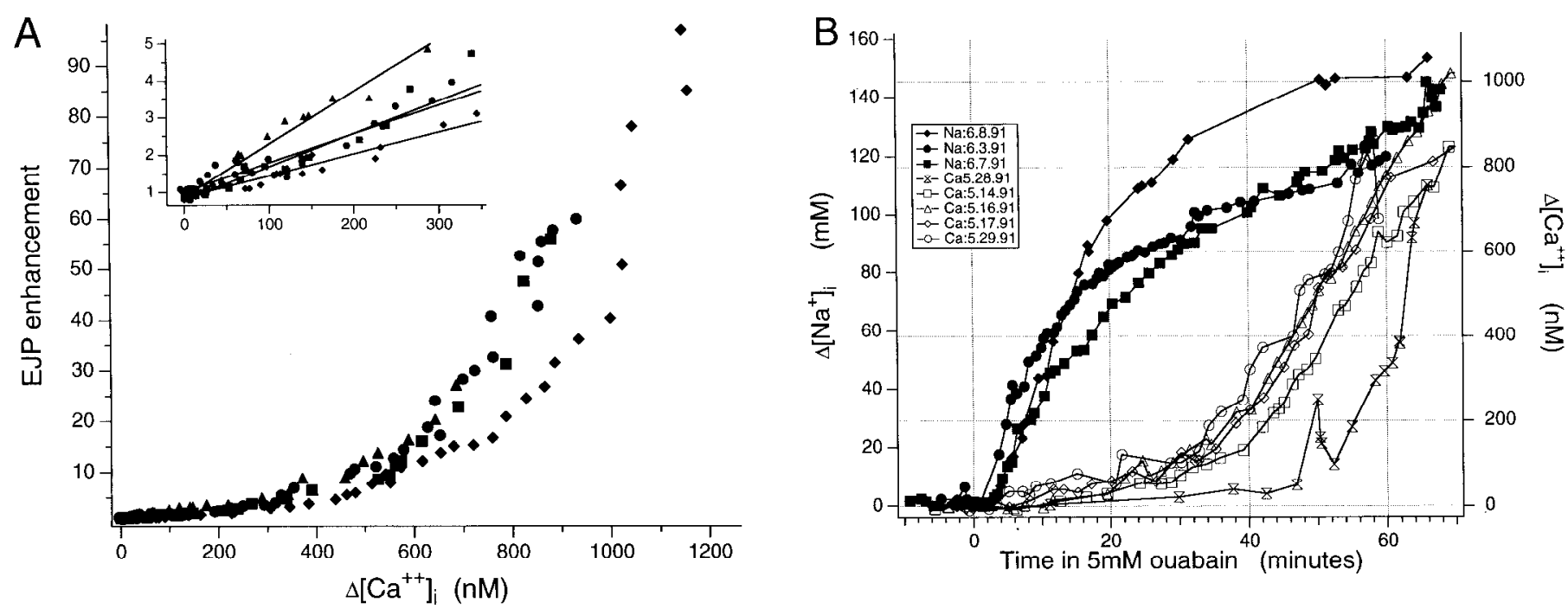

Figure 7. $A$, Effect of $1 \mathrm{~mm}$ ouabain on $\left[\mathrm{Ca}^{2+}\right]_{i}$ and ejp enhancement. Data from four of five of the preparations of $B$ are shown by different symbols. Inset shows detail of data for $\Delta\left[\mathrm{Ca}^{2+}\right]_{i}$ below $350 \mathrm{nM}$. Lines are linear fits to the data with correlation coefficients between 0.94 and 0.98 (see Table 1). B, Comparison of intracellular $\Delta\left[\mathrm{Na}^{+}\right]_{i}$ and $\Delta\left[\mathrm{Ca}^{2+}\right]_{i}$ following application of crayfish ringer containing $5 \mathrm{~mm}$ ouabain. [ $\left.\mathrm{Na}^{+}\right]_{i}$ estimated using the fluorescent $\mathrm{Na}^{+}$indicator SBFI in three preparations as indicated by solid symbols. Time course of increased [Ca $\left.{ }^{2+}\right]_{i}$ was measured in five other preparations. Date of each experiment is contained in the legend for reference back to Table 1 . The transient increase of [Ca $\left.{ }^{2+}\right]_{i}$ at $t=$ $50 \mathrm{~min}$ for experiment 5.28 .91 was the result of a $5 \mathrm{~Hz} 30 \mathrm{sec}$ test train of action potentials. Note the short delay between application of ouabain and the start of significantly increasing $\left[\mathrm{Na}^{+}\right]_{i}$ compared to the more slowly increasing $\left[\mathrm{Ca}^{2+}\right]_{i}$.

face of this fiber was $500 \mathrm{nM},\left[\mathrm{Ca}^{2+}\right]_{i}$ in terminals on the underside was about 450 nм.

\section{Effects of increased $\left[\mathrm{Ca}^{2+}\right]_{\mathrm{i}}$ caused by application of ouabain or monensin}

Inhibition of $\mathrm{Na}^{+} / \mathrm{K}^{+}$pump by ouabain elevates $\left[\mathrm{Ca}^{2+}\right]_{i}$, possibly by reducing $\mathrm{Na}^{+} / \mathrm{Ca}^{2+}$ exchanger-mediated $\mathrm{Ca}^{2+}$ removal (Charlton and Atwood, 1977; Zucker et al., 1991; Mulkey and Zucker, 1992) and synaptic transmission is enhanced. $\left[\mathrm{Na}^{+}\right]_{i}$ in presynaptic terminals measured with SBFI, began rising within $30 \mathrm{sec}$ of application of $5 \mathrm{~mm}$ ouabain. About $10 \mathrm{~min}$ after application of ouabain, when $\left[\mathrm{Na}^{+}\right]_{i}$ estimated from fluorescence SBFI measurements in other experiments has increased many tens of millimoles per liter (Fig. $7 \mathrm{~B}$ ), $\left[\mathrm{Ca}^{2+}\right]_{i}$ begins to increase above normal resting levels and at the same time synaptic transmission is enhanced (Fig. 7A). We did not compare the relationship between $\Delta\left[\mathrm{Ca}^{2+}\right]_{i}$ and augmentation before ouabain was applied. However, the relationship between $\Delta\left[\mathrm{Ca}^{2+}\right]_{i}$ and enhancement in the ouabain experiments was comparable to the relationship between $\Delta\left[\mathrm{Ca}^{2+}\right]_{i}$ and augmentation seen in other experiments at similar temperatures, with $\Delta\left[\mathrm{Ca}^{2+}\right]_{\text {, less }}$ than $350 \mathrm{~nm}$ (Fig. $7 A$ and experiments indicated by $a$ in Table 1). Interpreting the effect of ouabain-induced $\Delta\left[\mathrm{Ca}^{2+}\right]_{i}$ on ejp enhancement is complicated by the fact that broadening of the action potential and depolarization of the presynaptic terminal occurs with ouabain incubation (Charlton and Atwood, 1977; Mulkey and Zucker 1992; Delaney and Tank, unpublished observations). This broadening is least prominent shortly after ouabain application when $\left[\mathrm{Ca}^{2+}\right]_{i}$ has only increased a few hundred nanomoles per liter. Plots of ejp enhancement versus $\Delta\left[\mathrm{Ca}^{2+}\right]_{i}$ were reasonably well fit by a linear function up to 350 nм above basal (Fig. $7 A$, inset; Table 1) although evidence for nonlinearity is seen even at $250 \mathrm{~nm}$ above basal in some experiments, probably due to the effects of spike broadening and/ or slight presynaptic depolarization, which would increase the apparent slope of the relationship.

\section{Mejp frequency and evoked ejps at high residual $\left[\mathrm{Ca}^{2+}\right]_{\mathrm{i}}$}

Continuous application of ouabain for more than $40 \mathrm{~min}$ or application of more than $1 \mu \mathrm{M} \mathrm{Ca}{ }^{2+}$ ionophore increased $\left[\mathrm{Ca}^{2+}\right]_{i}$ to levels between 1 and $>2 \mu \mathrm{M}$ above basal. Ejp enhancement in excess of 50-fold was seen and the relationship between ejp enhancement and $\left[\mathrm{Ca}^{2+}\right]_{t}$ became highly nonlinear at $\left[\mathrm{Ca}^{2+}\right]_{i}$ between $600 \mathrm{nM}$ and $1 \mu \mathrm{M}$ above basal (Fig. 7A). As discussed above, spike broadening probably contributes to some of the enhancement resulting from ouabain, especially when $\Delta\left[\mathrm{Ca}^{2+}\right]_{i}$ is large. However, mejp frequency increased approximately linearly when $\Delta\left[\mathrm{Ca}^{2+}\right]_{i}$ was less than $500 \mathrm{nM}$, but in an increasingly nonlinear fashion as $\left[\mathrm{Ca}^{2+}\right]_{i}$ increased beyond $500 \mathrm{nM}$ above basal (Fig. 8; a similar effect was also scen with A23187). As in experiments where ouabain was used to raise $\left[\mathrm{Ca}^{2+}\right]_{i}$, mejp release rates more than 150 -fold greater than resting rates were associated with maintained $\Delta\left[\mathrm{Ca}^{2+}\right]_{i}$ above $2 \mu \mathrm{M}$. With both $\mathrm{Ca}^{2+}$ ionophore and ouabain the ejp eventually declined in amplitude and then failed, despite maintained or increasing spontaneous release. With $2 \mu \mathrm{M}$ ionophore peak enhancement of 10 20 -fold was seen before failure of the ejp. Mejp frequency continued to increase in several experiments despite failure of the ejp and even after $\left[\mathrm{Ca}^{2+}\right]_{t}$ increases had plateaued, suggesting that there may have been an additional slow time dependence to the enhancement. Alternatively, since we imaged surface terminals, the continued increase in mejp may reflect continued increases in $\left[\mathrm{Ca}^{2+}\right]_{i}$ in terminals between and underneath muscle fibers, the effect of which would be pronounced if the relationship between $\left[\mathrm{Ca}^{2+}\right]_{i}$ and increased mejp frequency becomes highly nonlinear at high $\left[\mathrm{Ca}^{3+}\right]_{i}$.

Injection of fura-2 to concentrations of 1-2 mm blocks action potential evoked ejps (greatly reducing movement) and slows recovery of $\left[\mathrm{Ca}^{2+}\right]_{i}$ after a train of action potentials. We examined the relationship between mejp frequency and $\left[\mathrm{Ca}^{2+}\right]_{i}$ following $\mathrm{Ca}^{2+}$ loading with 1 min long $65 \mathrm{~Hz}$ trains. During the train $\left[\mathrm{Ca}^{2+}\right]_{i}$ was greater than $2.5 \mu \mathrm{M}$. Averaging results from 


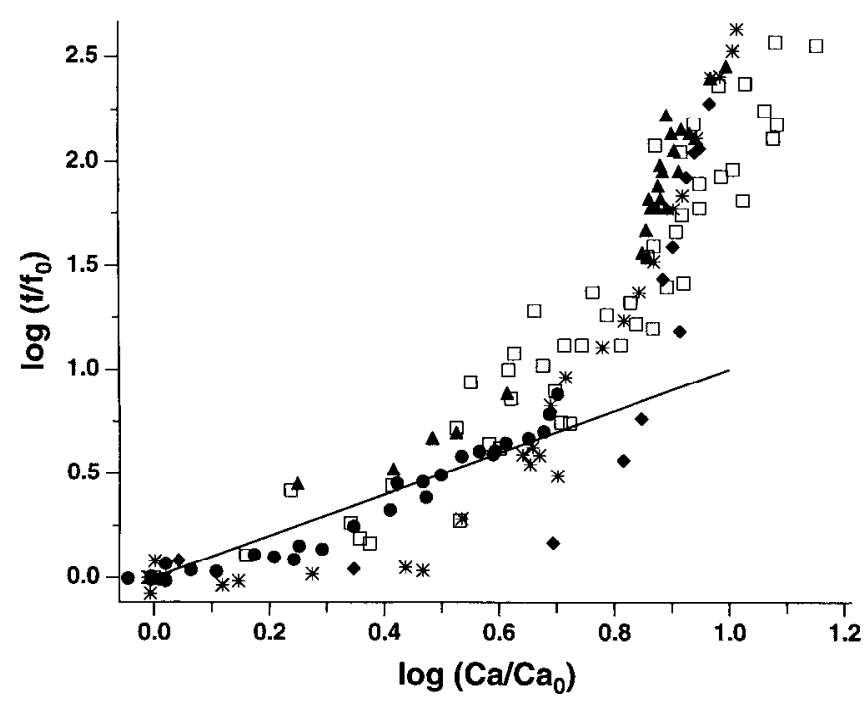

Figure 8. Effect of increased $\left[\mathrm{Ca}^{2+}\right]$, concentration on mejp frequency. Data are from the same experiments as those shown in Figure $7 A$, that is, with $1 \mathrm{~mm}$ ouabain, except those indicated by ${ }^{*}$, which were obtained in the absence of ouabain after $60 \mathrm{sec}$ duration $65 \mathrm{~Hz}$ trains with approximately $1 \mathrm{~mm}$ fura- 2 in presynaptic terminals to slow $\mathrm{Ca}^{2+}$ removal and block-evoked ejps. In different experiments $\left[\mathrm{Ca}^{2+}\right]_{i}$ before addition of ouabain was between 140 and $190 \mathrm{~nm}$. Straight line has slope of 1 as a reference.

several trains indicated that the relationship between mejp frequency and $\left[\mathrm{Ca}^{2+}\right]_{i}$ was approximately linear when $\left[\mathrm{Ca}^{2+}\right]_{i}$ was less than $600 \mathrm{nM}$, which typically occurred 12-15 sec after the offset of the train (Fig. 8). Accurate determination of the mejp frequency is difficult at these times because the frequency is low and variance high (Zucker and Lara Estralla, 1983). Between 0 and $10 \mathrm{sec}$ after the train (i.e., $\left[\mathrm{Ca}^{2+}\right]_{i}$ of $2.5-1 \mu \mathrm{M}$ ) the relationship between mejp and $\left[\mathrm{Ca}^{2+}\right]_{i}$ was nonlinear. The magnitude of the nonlinearity was similar to that seen during ouabaininduced $\left[\mathrm{Ca}^{2+}\right]$ increases.

It is important to note that the highly nonlinear effects of $\left[\mathrm{Ca}^{2+}\right]_{i}$ on ejps and mejps were all seen with $\Delta\left[\mathrm{Ca}^{2+}\right]_{i}$ several hundred nanomolar above the maximum associated with augmentation after trains. Therefore, rather than implying that augmentation and $\left[\mathrm{Ca}^{2+}\right]_{i}$ after trains are unrelated, these nonlinear effects may reflect activation or persistence of additional facilitation processes with $\mathrm{Ca}^{2+}$ sensitivities lower than those producing augmentation.

\section{Discussion}

The goal of our experiments was to test the hypothesis that elevated $\left[\mathrm{Ca}^{2+}\right]_{i}$ causes one form of synaptic enhancement: augmentation. Our strategy was to combine quantitative microfluorimetric measurements of presynaptic $\left[\mathrm{Ca}^{2+}\right]_{i}$ with quantitative electrophysiological measurements of synaptic strength during and after short trains of action potentials.

At normal temperatures and low exogenous $\mathrm{Ca}^{2+}$ buffer conditions $(<200 \mu \mathrm{M}$ fura-2), we found that the time course of recovery of $\left[\mathrm{Ca}^{2}\right]_{i}$ in presynaptic terminals matches the decay of the enhanced ejp during the period attributed to synaptic augmentation after a train of action potentials. This basic result builds upon our previously reported observation that a correlation between $\left[\mathrm{Ca}^{2+}\right]_{i}$ and enhancement is also present after intense stimulus trains that induce ptp (Delaney et al., 1989). To go beyond simple correlation and examine the hypothesis that $\left[\mathrm{Ca}^{2+}\right]_{i}$ causes synaptic enhancement, we designed our experiments to test if elevated $\left[\mathrm{Ca}^{2+}\right]_{i}$ is both necessary and sufficient and to make quantitative comparisons.

To test the necessity of $\Delta\left[\mathrm{Ca}^{2+}\right]_{i}$ for the enhancement, we changed the kinetics of $\mathrm{Ca}^{2+}$ buildup and recovery by introducing exogenous $\mathrm{Ca}^{2+}$ buffer into the presynaptic terminal. We also changed the temperature to change $\mathrm{Ca}^{2+}$ removal kinetics. The correlation between $\Delta\left[\mathrm{Ca}^{2+}\right]_{i}$ and enhancement was observed under all of these conditions. To test the sufficiency of $\Delta\left[\mathrm{Ca}^{2+}\right]_{i}$ for the enhancement we used $\mathrm{Ca}^{2+}$ ionophore or a $\mathrm{Na}^{+} /$ $\mathrm{K}^{+}$pump blocker to increase presynaptic residual $\mathrm{Ca}^{2+}$ without action potentials. Again, the correlation between $\left[\mathrm{Ca}^{2+}\right]_{i}$ and enhancement was observed and it was quantitatively similar to the relationship after a train of action potentials.

Thus, the principal conclusion of our work is that increased $\left[\mathrm{Ca}^{2+}\right]_{i}$ in the range of $1 \mu \mathrm{M}$-because it is both necessary and sufficient-causes enhanced transmitter release during augmentation at the crayfish $\mathrm{nmj}$. In following sections, we incorporate our quantitative measurements of residual $\left[\mathrm{Ca}^{2+}\right]_{i}$, augmentation, ptp, and the buildup of activity-dependent enhancement during trains into a multicomponent model for these phenomena similar to that of Magleby and co-workers (Magleby, 1987). This analysis helps define what forms of biochemical/biophysical mechanisms could be responsible for the calcium-dependent production of augmentation and ptp. It also suggests how our experimental results can provide insight into the synaptic facilitation (F1 and F2) that occurs on a shorter time scale at this synapse. A general theme throughout the discussion is that the effects of $\mathrm{Ca}^{2+}$ ions on transmitter release and its enhancement must be considered in a spatiokinetic framework.

\section{Spatiokinetics of $\mathrm{Ca}^{2+}$-dependent reactions and measurements} of calcium concentration

During and immediately after each action potential that invades a presynaptic terminal, very high $\mathrm{Ca}^{2+}$ concentrations, estimated to be $>100 \mu \mathrm{M}$, are present in the vicinity of the mouths of the $\mathrm{Ca}^{2+}$ channels along the inner surface of the plasma membrane. These rapid, high transients produce the rapid exocytosis of vesicles containing neurotransmitter substances from presynaptic nerve terminals (Simon and Llinás, 1985; Zucker and Fogelson, 1986; Roberts et al., 1990; Augustine et al., 1991; Llinás et al., 1992). Dissipation of these transients by diffusion and buffering adds a small $\mathrm{Ca}^{2+}$ load to the longer-lasting spatially uniform $\left[\mathrm{Ca}^{2+}\right]_{i}-$ termed the residual free calcium concentration - of the terminal. In the crayfish terminal, we estimate that the load from each action potential increases the $\left[\mathrm{Ca}^{2+}\right]_{i}$ in the volume of the terminal by about $10 \mathrm{~nm}$ (Tank et al., 1994). In crayfish, the removal of this residual $\mathrm{Ca}^{2+}$ is approximatcly exponential with a time constant of about $6 \mathrm{sec}$ at $20^{\circ} \mathrm{C}$ in the absence of exogenous $\mathrm{Ca}^{2+}$ buffers.

The high-concentration, fast, highly localized transient and the low-concentration, slow, spatially uniform residual $\mathrm{Ca}^{2+}$ represent two distinct spatiotemporal domains. They are different "compartments" that must be considered in analyzing the action $\mathrm{Cf}^{2+}$ on intracellular biochemistry, like that underlying synaptic enhancement, and also in the use of $\mathrm{Ca}^{2+}$ indicator molecules like fura-2 to measure $\left[\mathrm{Ca}^{2+}\right]_{i}$.

The influence of the spatiotemporal $\mathrm{Ca}^{2+}$ dynamics on $\mathrm{Ca}^{2+}$. dependent reactions is in turn dependent on the location of the molecules involved in the reaction and their kinetic rate constants for $\mathrm{Ca}^{2+}$ binding and unbinding. We call these the spatiokinetic properties of the reaction. One clear example of these 
properties is the effect of exogenous intracellular $\mathrm{Ca}^{2+}$ buffers on synaptic release. For release to be driven off the high transient pulse of $\mathrm{Ca}^{2+}$, the $\mathrm{Ca}^{2+}$-dependent release molecules must be located near the mouth of $\mathrm{Ca}^{2+}$ channels and they must be kinetically fast. An exogenous buffer can interfere with release if two separate conditions are satisfied. First, the buffer must be in the right location near the calcium channel mouth. This condition is usually fulfilled by freely diffusible molecules like BAPTA and EDTA. Second, its forward kinetic rate for binding $\mathrm{Ca}^{2+}$ ions must be fast enough so that it competes for the $\mathrm{Ca}^{2+}$ entering the cytoplasm (Adler et al., 1991). This latter kinetic constraint holds for BAPTA, but not for EDTA. Thus, introduction of BAPTA blocks synaptic transmission, but an equivalent amount of EDTA does not, despite the fact that both chelators have a high affinity for $\mathrm{Ca}^{2+}$. On the other hand, both EDTA and BAPTA will affect the slow buildup and recovery of residual $\mathrm{Ca}^{2+}$ because they are distributed in a spatially uniform way and their kinetic rates are fast compared to this process. In our experiments we have exploited these differences by using EDTA to alter $\left[\mathrm{Ca}^{2+}\right]_{i}$ buildup and recovery kinetics without altering release. More importantly, the spatiokinetic framework also applies to the $\mathrm{Ca}^{2+}$-dependent processes that modulate release and underlie short-term synaptic enhancement. Using our experimental results, we use this framework to constrain the spatial location, $\mathrm{Ca}^{2+}$ affinity, and relative kinetic rate constants for these $\mathrm{Ca}^{2+}$-dependent reactions.

The same spatiotemporal aspects of $\mathrm{Ca}^{2+}$ dynamics and spatiokinetic framework of $\mathrm{Ca}^{2+}$-dependent reactions are also important in interpretation of our fura- 2 measurements. The recovery rates we measured were slow compared to the estimated $\mathrm{Ca}^{2+}$ ion diffusional equilibrium time in these terminals (Smith and Zucker, 1980). Thus, from the spatial perspective, fura-2 reports the $\left[\mathrm{Ca}^{2+}\right]_{i}$ after a train that is approximately uniform over the intracellular space of the terminal. From the kinetic perspective, the recovery rates of $\left[\mathrm{Ca}^{2+}\right]_{i}$ that we measured are slow compared to the characteristic equilibration times of fura-2 with $\mathrm{Ca}^{2+}$ ions (Kao and Tsien, 1988). Thus, the indicator molecule-being dependent on a $\mathrm{Ca}^{2+}$-dependent chemical reaction-is always in equilibrium with the free $\mathrm{Ca}^{2+}$ ions and the observed time course of the indicator fluorescence reflects only the removal of $\mathrm{Ca}^{2+}$ ions from the cytoplasm.

Measurements made during trains of action potentials are, in principle, not as easily interpreted. How does the $\left[\mathrm{Ca}^{2+}\right]_{i}$ measured with fura-2 during a train compare to the $\left[\mathrm{Ca}^{2+}\right]$ at the sites where $\mathrm{Ca}^{2+}$ acts in the interval between action potentials? For several reasons we feel the spatiotemporal average we measure with fura- 2 is not strongly influenced by the transiently high submembrane $\left[\mathrm{Ca}^{2+}\right]$ present immediately after an action potential. The most compelling evidence that the $\left[\mathrm{Ca}^{2+}\right]_{i}$ measured during a train is approximately equal to the $\left[\mathrm{Ca}^{2+}\right]_{i}$ in the bulk of the terminal is that immediately after the offset of a train of action potentials we do not observe a large and sudden drop in fura-measured $\left[\mathrm{Ca}^{2+}\right]_{i}$. If the transient were significantly biasing our estimate of the average $\left[\mathrm{Ca}^{2+}\right]_{i}$ in the terminal, we would expect the apparent $\left[\mathrm{Ca}^{2+}\right]_{i}$ to show an initial rapid drop within about $100 \mathrm{msec}$ after the offset of the train as the diffusional gradients set up by the opening of channels during an action potential collapsed. Therefore, during $15.2 \mathrm{~Hz}$ stimulation, with $0.066 \mathrm{sec}$ between action potentials, the spatiotemporally averaged $\left[\mathrm{Ca}^{2+}\right]_{i}$ reported by fura- 2 is much closer to the $\left[\mathrm{Ca}^{2+}\right]$ present under the membrane immediately before invasion of the terminal by each action potential than a milli- second after it. That is, fura- 2 predominantly measures the spatially averaged "residual $\left[\mathrm{Ca}^{2+}\right]$."

We can understand the insensitivity of our measurements to the localized, high-concentration $\mathrm{Ca}^{2+}$ pulse produced by action potentials at the inner membrane surface near $\mathrm{Ca}^{2+}$ channels by noting that several effects conspire to reduce the influence of this $\mathrm{Ca}^{2+}$ on the $\left[\mathrm{Ca}^{2+}\right]_{i}$ reported by fura- 2 . Within the first few milliseconds after an action potential, the volume occupied by the $\mathrm{Ca}^{2+}$ ions is small relative to the total volume of the terminal because of the time required for diffusion of $\mathrm{Ca}^{2+}$ away from the channel mouth. Therefore, although $\left[\mathrm{Ca}^{2+}\right]$ is high, it can only interact with a small proportion of the total fura in the terminal and contributes a small amount to the total fluorescent signal measured across the volume of the terminal. This volume effect is heightened by the fact that at high $\left[\mathrm{Ca}^{2+}\right]_{i}$ when fura is saturated with $\mathrm{Ca}^{2+}$, the change in ratio becomes small for a given increment in $\left[\mathrm{Ca}^{2+}\right]_{i}$.

\section{Alterations of $\mathrm{Ca}^{2+}$ kinetics: the necessity of $\mathrm{Ca}^{2+}$ in augmentation}

To test the necessity of $\mathrm{Ca}^{2+}$ in the production of augmentation, we changed $\mathrm{Ca}^{2+}$ recovery kinetics and examined how the kinetics of synaptic enhancement were changed. Our basic result, embodied in Figure 3, is that alteration of $\mathrm{Ca}^{2+}$ recovery kinetics produce concomitant alterations in the kinetics of synaptic enhancement. Slowing the rate of rise of $\mathrm{Ca}^{2+}$ during a train by increasing exogenous buffer capacity also slows the buildup of a component of the total synaptic enhancement seen during trains. When $\mathrm{Ca}^{2+}$ levels plateau during trains of action potentials, synaptic enhancement also reaches a constant level. The relationship between the slowly building $\mathrm{Ca}^{2+}$ and the slowly building synaptic enhancement during trains is quantitatively similar to the relationship between $\Delta\left[\mathrm{Ca}^{2+}\right]_{i}$ and enhancement after trains. These experiments demonstrate the necessity of elevated $\left[\mathrm{Ca}^{2+}\right]_{i}$ in the production of augmentation and suggest that augmentation-like processes are driven by $\Delta\left[\mathrm{Ca}^{2+}\right]_{i}$ during trains that also produce short-term facilitation. Swandulla et al. (1991) also conclude that elevated $\mathrm{Ca}^{2+}$ is necessary for a slowly decaying form of synaptic enhancement at squid giant synapse that is similar to augmentation at nmjs.

\section{Augmentation is a temperature-dependent process}

Although increased buffer capacity could slow greatly the rate of recovery of $\Delta\left[\mathrm{Ca}^{2+}\right]_{i}$ and the decay of augmentation after a train, it did not appreciably change the relationship between $\Delta\left[\mathrm{Ca}^{2+}\right]_{i}$ and enhancement. In contrast, reducing the temperature decreased the slope of the relationship between augmentation and $\left[\mathrm{Ca}^{2+}\right]_{i}$ two- to threefold per $10^{\circ} \mathrm{C}$. Transmitter release itself is highly temperature sensitive (e.g., Llinás et al., 1987) but this effect is compensated during estimation of augmentation by comparing posttetanus ejps to pretetanus ejps at each temperature. The additional effect of temperature on augmentation suggests release and enhancement are separate biochemical processes.

\section{Increasing $\mathrm{Ca}^{2+}$ with ionophores: the sufficiency of $\mathrm{Ca}^{2+}$ in augmentation}

Our experiments strongly suggest that the residual $\mathrm{Ca}^{2+}$ present after a train drives the processes responsible for augmentation and by analogy ptp since several independent modifications of $\mathrm{Ca}^{2+}$ recovery kinetics lead to a concomitant change in ejp enhancement decay. However, since trains of action potentials are 
used to elevate presynaptic $\left[\mathrm{Ca}^{2+}\right]_{i}$, it is possible that $\Delta \mathrm{Ca}^{2+}$ acts in conjunction with some other product of presynaptic activity (e.g., voltage or $\mathrm{Na}^{+}$) to produce synaptic enhancement (Bittner and Baxter, 1991). Elevation of $\left[\mathrm{Ca}^{2+}\right]_{i}$ with ouabain in the absence of action potentials produces synaptic enhancement that initially (i.e., at low $\left[\mathrm{Ca}^{2}\right.$ ] , values) is comparable to that after trains of action potentials. These experiments indicate that increased $\left[\mathrm{Ca}^{2+}\right]_{i}$ can produce synaptic enhancement in the absence of electrical activity, but ouabain application is accompanied by $\mathrm{Na}^{+}$accumulation (Fig. $7 B$ ) and by action potential broadening and presynaptic depolarization, compromising quantitative comparisons between presynaptic $\left[\mathrm{Ca}^{2+}\right]_{i}$ and synaptic enhancement. Similar problems are associated with experiments in which the $\mathrm{Na}^{+}$ionophore monensin is used to elevatc $\left[\mathrm{Ca}^{2+}\right]_{i}$ indirectly (Mulkcy and Zucker, 1992).

We applied low concentrations of $\mathrm{Ca}^{2+}$ ionophore 4-bromoA23187 to produce $\Delta\left[\mathrm{Ca}^{2+}\right]_{i}$ similar to those observed during augmentation but without concomitant $\mathrm{Na}^{+}$accumulation. The magnitude of ejp enhancement produced by $\left[\mathrm{Ca}^{2+}\right]_{i}$ elevation with ionophore is comparable to that associated with increased $\left[\mathrm{Ca}^{2+}\right]_{i}$ during augmentation, suggesting that augmentation does nol require synergism between residual $\mathrm{Ca}^{2+}$ and some other activity-related product resulting from action potential invasion.

$\left[\mathrm{Na}^{+}\right]$buildup and recovery with trains of action potentials are not expected to be significantly affected by the addition of $\mathrm{Ca}^{2+}$ buffer, so the quantitative and temporal correspondence of $\left[\mathrm{Ca}^{2+}\right]_{i}$ with enhancement after a train as recovery is slowed with exogenous $\mathrm{Ca}^{2+}$ buffer further suggests $\mathrm{Na}^{+}$does not play a direct role in synaptic enhancement. Also, during moderate frequency trains in terminals that have not been injected with exogenous buffer, $\left[\mathrm{Ca}^{2+}\right]_{i}$ builds to a plateau level in $10-15 \mathrm{sec}$ while $\left[\mathrm{Na}^{+}\right]$continues to build up for many tens of seconds (Delaney and Tank, unpublished observations). Therefore, the magnitude of $\left[\mathrm{Na}^{+}\right]_{i}$ at the end of a moderate-frequency train varies with the duration of stimulation, which is not characteristic of $\Delta\left[\mathrm{Ca}^{2+}\right]_{i}$ or augmentation.

In summary, the enhancement of synaptic transmission seen during the period ascribed to augmentation can be quantitatively accounted for by the residual $\left[\mathrm{Ca}^{2+}\right]_{6}$ left over after a train of action potentials without the need to postulate additional activity-dependent processes.

Further evidence for causality: $\mathrm{Ca}^{2+}$ and augmentation-like enhancement during trains of stimuli

In this study we have largely restricted our presentation of $\Delta\left[\mathrm{Ca}^{2+}\right]_{i}$ measurements and synaptic enhancement to the period commencing approximately $1 \mathrm{sec}$ after the end of the train so as to be confident that the spatial average of $\left[\mathrm{Ca}^{2+}\right]_{i}$ across the diameter of the terminal (which is what is measured by fura-2) was similar to the $\Delta\left[\mathrm{Ca}^{2+}\right]_{i}$ at the inner surface of the presynaptic membrane and to avoid complications resulting from the rapid decay of F1 and F2 facilitation. Thus, after a train, few assumptions are required in order to relate fura-2 fluorescence to $\Delta\left[\mathrm{Ca}^{2+}\right]_{i}$ at facilitatory sites and thus $\Delta\left[\mathrm{Ca}^{2+}\right]_{i}$ to augmentation. Nonetheless, some interesting conclusions can be drawn about the relationship between $\left[\mathrm{Ca}^{2+}\right]_{i}$ and the faster-decaying forms of activity-dependent synaptic enhancement, F1 and F2.

Are the same $\mathrm{Ca}^{2+}$-dependent processes that are present after a train of action potentials activated by $\mathrm{Ca}^{2+}$ accumulating during a train? To address this issue we compared the relationship between $\Delta\left[\mathrm{Ca}^{2+}\right]_{i}$ and synaptic enhancement after a train to the relationship between $\Delta\left[\mathrm{Ca}^{2+}\right]_{i}$ and synaptic enhancement during a train, in terminals injected with exogenous $\mathrm{Ca}^{2+}$ buffer. We compensated for $\mathrm{F} 1$ and $\mathrm{F} 2$ during the train by dividing the observed total synaptic enhancement by an estimate of facilitation that is based on a model in which facilitation builds rapidly in a few seconds to a constant plateau value. The constant value used in the model was about $90 \%$ of the total enhancement seen 1-2 sec after the start of the train, when $\left[\mathrm{Ca}^{2+}\right]_{i}$ had increased less than $50 \mathrm{~nm}$. This procedure is consistent with a multiplicative relationship between $F 1, F 2$, and augmentation as proposed by Magleby and colleagues (Magleby, 1987, for review). We found that the relationship between the remaining synaptic enhancement and $\Delta\left[\mathrm{Ca}^{2+}\right]_{i}$ during the train was linear and quantitatively similar to that observed between residual $\left[\mathrm{Ca}^{2+}\right]_{\text {, }}$ and augmentation after the train.

These data lead us to conclude that $F 1$ and $F 2$ are processes that occur largely independent of the average residual free $\left[\mathrm{Ca}^{2+}\right]_{i}$ present in the terminal a few tens of milliseconds after an action potential (i.e., the $\left[\mathrm{Ca}^{2+}\right]$ measured by fura-2). During a train of action potentials, F1 and F2 appear to "ignore" the buildup of $\left[\mathrm{Ca}^{2+}\right]_{i}$ in the bulk of the cytoplasm while another component of the total synaptic enhancement closely follows the change in $\Delta\left[\mathrm{Ca}^{2+}\right]_{i}$. If $\mathrm{F} 1$ and $\mathrm{F} 2$ were not independent of fura-measured $\left[\mathrm{Ca}^{2+}\right]_{i}$, then as $\left[\mathrm{Ca}^{2+}\right]_{i}$ increased during the train, the ejp enhancement would have increased by an amount greater than expected based on the augmentation after the train.

To summarize, during action potential trains there is an initial rapid synaptic enhancement (F1/F2) that is independent of the $\left[\mathrm{Ca}^{2+}\right]_{i}$ measured with fura- 2 and a slower phase that is directly dependent upon the fura-measured $\left[\mathrm{Ca}^{2+}\right]_{i}$. Further, the slow phase is dependent upon $\left[\mathrm{Ca}^{2+}\right]_{i}$ in approximately the same quantitative manner as augmentation after the train, if we assume a multiplicative relationship between the initial rapid phase and the slower phases of synaptic enhancement during trains. Our data do not exclude the possibility that $F 1$ or F2 are dependent upon freely diffusing $\mathrm{Ca}^{2+}$ or $\mathrm{Ca}^{2+}$ persistently bound to a facilitating site (Balnave and Gage, 1974; Stanley, 1986). They do, however, suggest that if $\mathrm{Ca}^{2}+$ has a role in $\mathrm{F} 1$ or F2, this role is mediated by a relatively low-affinity binding site (see also Yamada and Zucker, 1992).

\section{What and where is the $\mathrm{Ca}^{2+}$-activated molecule mediating augmentation?}

We have demonstrated that augmentation is caused by a $\mathrm{Ca}^{2+}$. dependent reaction driven by the slowly changing, low-concentration residual $\left[\mathrm{Ca}^{2+}\right]_{i}$. Since augmentation can be driven by relatively low $\left[\mathrm{Ca}^{2+}\right]_{i}$ and the forward kinetics of augmentation do not need to be as fast as those for evoked release, there is no need to postulate that the augmentation machinery is localized near $\mathrm{Ca}^{2+}$ channels or release sites. Furthermore, the fact that during trains there is an augmentation-like enhancement correlated with fura- 2 measured $\Delta\left[\mathrm{Ca}^{2+}\right]_{i}$ implies that augmentation, like fura-2 fluorescence, is dominated by processes occurring some distance from the membrane surface, either free in the cytoplasm or at vesicle membranes some distance away from the inner terminal membrane. Thus, $\mathrm{Ca}^{2+}$ almost certainly acts as a second messenger at a site physically distinct from that mediating fusion (or facilitation) to enhance release during augmentation. Data such as those of Figure 4 suggest to us a model in which augmentation increases the availability of vesicles for release while facilitation increases the probability of releasing an available vesicle. The total increased probability of release 
of vesicles is then determined by the product of these two independent processes. Lin and Llinás (1993) proposed that mobilization of vesicles could account for several features of slow synaptic enhancement at crab mechanoreceptor synapse. Llinás et al. (1985) proposed a pool of vesicles is normally tethered to cytoskeletal elements by unphosphorylated synapsin and is therefore not immediately available for release. Increased $\mathrm{Ca}^{2+}$ activates CAM kinase II through activation of calmodulin and phosphorylates synapsin, which releases tethered vesicles, making them available to bind to the release site. The result is a greater release probability to subsequent action potentials. To be consistent with our work, the relatively low (several hundred nanomolar) $\Delta\left[\mathrm{Ca}^{2+}\right]_{i}$ we have measured would only have to activate the CAM kinase system in such a way that the net effect on enhanced release was approximately linear in $\left[\mathrm{Ca}^{2+}\right]_{i}$. Thus, our data do not necessarily bear on the issue of stoichiometry of the $\mathrm{Ca}^{2+}$ binding to molecules responsible for augmentation.

Application of serotonin to the crayfish nmj produces a potentiation of release without affecting F1/F2 facilitation (Dudel, 1988). We have previously shown that serotonergic enhancement does not depend on changes in residual $\mathrm{Ca}^{2+}$ or $\mathrm{Ca}^{2+}$ influx per action potential (Delaney et al., 1991). One intriguing possibility is that both augmentation and neuromodulator-induced enhancement act to increase the availability of vesicles for release, perhaps by converging onto the same final biochemical pathway such as the phosphorylation of synapsin. They would differ in the method of kinase activation.

\section{A spatiokinetic model of enhancement and release}

Katz and Miledi (1968) first proposed that residual $\mathrm{Ca}^{2+}$ was responsible for activity-dependent short-term enhancement (F1/ F2). The basic idea of their classical "residual $\mathrm{Ca}^{2+}$ " model was more transmitter vesicles were released because the action potential-associated $\mathrm{Ca}^{2+}$ influx sums with the residual $\mathrm{Ca}^{2+}$ left over from earlier action potentials to produce a higher peak $\left[\mathrm{Ca}^{2+}\right]$ at release sites. The nonlinear relationship typically observed between extracellular $\left[\mathrm{Ca}^{2+}\right]$ and release was extended to facilitation of release in order to account for the fact that release is over in a millisecond of the end of the action potential but facilitation persists for many tens of milliseconds.

In a previous study, Delaney et al. (1989) directly tested the application of this idea to posttetanic potentiation (ptp), a longer-lasting form of enhancement. They determined that after long-lasting high-frequency stimulation the slow return of $\left[\mathrm{Ca}^{2+}\right]_{i}$ to prestimulus levels matched the slow recovery of synaptic strength at crayfish $\mathrm{nmj}$. This correlation suggested that residual $\Delta\left[\mathrm{Ca}^{2+}\right]_{i}$ was somehow responsible for synaptic enhancement during ptp. Delaney et al. (1989) concluded that the residual $\mathrm{Ca}^{2+}$ model of Katz and Miledi (1968) for facilitation was not applicable to the correlation between $\Delta\left[\mathrm{Ca}^{2+}\right]_{i}$ and enhancement after ptp producing trains because the magnitude of enhancement over which ptp was linearly correlated with $\Delta\left[\mathrm{Ca}^{2+}\right]_{i}$ was greater than expected, even for a 5 th power relationship between $\left[\mathrm{Ca}^{2+}\right]$ and release.

Since ptp after intense tetanic stimulation and augmentation after more moderate tetanus are associated with comparable elevations of $\left[\mathrm{Ca}^{2+}\right]_{i}$ (typically $<1 \mu \mathrm{M}$ ), it seems reasonable to conclude that increased residual free $\left[\mathrm{Ca}^{2+}\right]_{i}$ is causal to the production of both ptp and augmentation and that perhaps both are the result of the same cellular processes; ptp is due to longerlasting elevation of $\left[\mathrm{Ca}^{2+}\right]_{i}$ after more intense stimulation, rather than the initiation of distinct biochemical reactions (Delaney and Tank, 1991). However, the relationship between ptp and $\left[\mathrm{Ca}^{2+}\right]_{i}$ reported by Delaney et al. (1989) was approximately twice as large as the relationship between $\left[\mathrm{Ca}^{2+}\right]_{i}$ and augmentation in experiments presented here done at comparable temperatures $\left(21^{\circ} \mathrm{C}\right)$. Unlike augmentation-producing trains, stimulus trains sufficient to produce ptp also usually produce long-term facilitation (LTF; Wojtowicz and Atwood, 1986) of about 1.5-2-fold, which remains essentially constant during the entire duration of ptp. LTF between 1.3- and 2.8-fold was observed in the experiments of Delaney et al. (1989), at times after trains when $\Delta\left[\mathrm{Ca}^{2+}\right]_{i}=0$ was not compensated for when calculating the relationship between $\Delta\left[\mathrm{Ca}^{2+}\right]_{i}$ and ptp. The apparently greater sensitivity of ptp to $\Delta\left[\mathrm{Ca}^{2+}\right]_{i}$ compared to augmentation would be accounted for by a multiplicative effect of a $\mathrm{Ca}^{2+}$-independent LTF. Recent preliminary experiments support this explanation for the quantitative difference between the $\left[\mathrm{Ca}^{2+}\right]_{i}$-enhancement relationship reported by Delaney et al. (1989), and that reported here (Delaney and Tank, unpublished observations).

With the work we have presented here, we can go beyond rejection of the simple residual $\mathrm{Ca}^{2+}$ model. Our data add to the growing literature that suggests that the release and enhancement processes must be considered in a more sophisticated spatiokinetic framework. Table 2 summarizes our current view of the spatial and kinetic characteristics of transmitter release and various frequency-dependent synaptic enhancement processes. One of our goals in summarizing the data in this way is to attempt to explain the phenomenological theory of synaptic enhancement put forward by Magleby and co-workers (see Eq. 1) by proposing multiple, independent processes acting in parallel with different $\mathrm{Ca}^{2+}$ dependencies produced by their different spatiokinetic properties.

In general, the spatiokinetic framework helps to explain how $\mathrm{Ca}^{2+}$-dependent processes mediated by low- and high-affinity $\mathrm{Ca}^{2+}$-binding sites can coexist and yet act independently. The basic release process itself responds to transiently high $\left[\mathrm{Ca}^{2+}\right.$, present near open $\mathrm{Ca}^{2+}$ channel mouths during an action potential, to evoke transmitter release. Calcium concentrations near release sites are likely $100-200 \mu \mathrm{M}$ or more (Llinás et al., 1992; Augustine et al., 1991), yet release is sensitive to small changes in $\mathrm{Ca}^{2+}$ influx. This implies that the effective $\mathrm{Ca}^{2+}$ affinity of the molecule(s) responsible for evoked transmitter release is low. Unlike transmitter release, $\mathrm{F} 1$ and $\mathrm{F} 2$ facilitation are not reduced by lowering extracellular $\left[\mathrm{Ca}^{2+}\right] 10$-fold (Linder, 1974; Zucker, 1974b; Dudel, 1981). If $\mathrm{Ca}^{2+}$ is activating facilitation, then this is consistent with saturation of the activating sites at reduced extracellular $\left[\mathrm{Ca}^{2+}\right]$ by the reduced, but nonetheless relatively high $\left[\mathrm{Ca}^{2+}\right]_{i}$ (perhaps tens of $\mu \mathrm{M}$ ) present at the membrane surface shortly after action potential-mediated $\mathrm{Ca}^{2+}$ channel openings. If $\mathrm{Ca}^{2+}$ binding sites are saturated by the $\left[\mathrm{Ca}^{2+}\right]$ produced by a single action potential, why does $\mathrm{F} 1 / \mathrm{F} 2$ increase with repeated stimulation? One reason may reflect the fact that only a small portion of the $\mathrm{Ca}^{2+}$ channels in a presynaptic terminal open during each action potential. Thus, the accumulation of F1/F2 could partly represent the accumulation of "units" of facilitation from the opening of different channels with successive action potentials. "Facilitated" vesicles could be vesicles located next to a channel that opened which were exposed to high $\left[\mathrm{Ca}^{2+}\right]$ but did not release, or vesicles located slightly distant from a channel that opened which remain facilitated until an immediately adjacent channel opens during a subsequent action potential to provide the very high $\left[\mathrm{Ca}^{2+}\right]$ 
Table 2. Possible calcium-dependent characteristics of activity-dependent synaptic enhancement at crayfish nmjs

\begin{tabular}{|c|c|c|c|c|}
\hline & $\begin{array}{l}\text { Possible Ca affinity } \\
\left(K_{D}\right)\end{array}$ & $\begin{array}{l}\text { Effective } \mathrm{Ca} \\
\text { forward binding } \\
\text { rate }\end{array}$ & $\begin{array}{l}\text { Termination } \\
\text { effectively } \\
\text { determined by }\end{array}$ & $\begin{array}{l}\text { Enhance- } \\
\text { ment factor } \\
\text { (over } \\
\text { sponta- } \\
\text { neous) }\end{array}$ \\
\hline Evoked release & Low, likely $>100 \mu \mathrm{M}$ & Very fast & Diffusion of $\mathrm{Ca}$ & $100-1000$ \\
\hline $\mathrm{F} 1$ & $\begin{array}{l}\text { Moderate, possibly } \\
\text { about } 10-20 \mu \mathrm{M}\end{array}$ & Fast & $\begin{array}{l}\text { Unbinding of } \mathrm{Ca} \text { or re- } \\
\text { verse reaction }\end{array}$ & $1-5$ \\
\hline F2 & $\begin{array}{c}\text { Moderate, possibly } \\
\text { about } 10-20 \mu \mathrm{M}\end{array}$ & Fast or moderate & $\begin{array}{l}\text { Diffusion of } \mathrm{Ca} \text { or un- } \\
\text { binding or reverse re- } \\
\text { action }\end{array}$ & $1-5$ \\
\hline Augmentation & High $\approx 1-3 \mu \mathrm{M}$ & Slow or fast & Free Ca removal & $1-5$ \\
\hline PTP & High $\approx 1-3 \mu \mathrm{M}$ & Slow or fast & Free Ca removal & $1-5$ \\
\hline LTF & Probably none ${ }^{a}$ & NA & Not free Ca removal ${ }^{b}$ & $1-2$ \\
\hline
\end{tabular}

${ }^{a}$ Wojtowicz and Atwood (1988).

${ }^{h}$ Delaney et al. (1989).

required for release. Their probability of release would be enhanced by their previous exposure to moderate to high $\left[\mathrm{Ca}^{2+}\right]$.

The apparently high $\mathrm{Ca}^{2+}$ affinity of the processes mediating augmentation and ptp results in a similar paradox in the face of the high $\left[\mathrm{Ca}^{2+}\right]$ required to evoke transmitter release: since the peak $\left[\mathrm{Ca}^{2+}\right]$ is very high when $\mathrm{Ca}^{2+}$ channels are opened by an action potential, why isn't augmentation (or ptp) maximally activated by the first or first few action potentials in a train? Also, why is augmentation reduced by EDTA while evoked transmitter release is largely unaffected? The answers may lie in the forward kinetics of $\mathrm{Ca}^{2+}$ binding, the location of the site of $\mathrm{Ca}^{2+}$ action relative to open $\mathrm{Ca}^{2+}$ channels, and turnover rates of $\mathrm{Ca}^{2+}$-activated enzyme processes, rather than in cooperativity between $\mathrm{Ca}^{2+}$ ions for release. In order to act as a temporally faithful transducer of neural activity from one cell to another, phasic transmitter release must start and stop rapidly after an action potential, so transmitter release sites are located extremely close to the site of $\mathrm{Ca}^{2+}$ influx and the binding of $\mathrm{Ca}^{2+}$ to the effector site is fast. As a modulatory process, augmentation is not limited by these constraints and separation of augmentation and release can occur even if the $\left[\mathrm{Ca}^{2+}\right]$ changes occur in the same physical "compartment." For example, even if the $\mathrm{Ca}^{2+}$-binding molecule mediating augmentation is near the site of $\mathrm{Ca}^{2+}$ influx, if the forward rate of $\mathrm{Ca}^{2+}$ binding is slow the buildup of augmentation would still be largely insensitive to the large $\left[\mathrm{Ca}^{2+}\right]$ transient. Alternatively, if the biochemical process that produces augmentation by binding $\mathrm{Ca}^{2+}$ is located some distance away from an open $\mathrm{Ca}^{2+}$ channel, then the forward rate is not relevant since the concentration gradient of $\mathrm{Ca}^{2+}$ rapidly declines with distance away from an open channel mouth. In this model, the low $\left[\mathrm{Ca}^{2+}\right]$ capable of augmenting release does not simultaneously activate the site responsible for evoked release (or $\mathrm{F} 1 / \mathrm{F} 2$ if these are $\mathrm{Ca}^{2}$ dependent) because of a large difference in $\mathrm{Ca}^{2+}$ binding affinity between the two sites.

Even if, as our experiments demonstrate, augmentation is driven by $\left[\mathrm{Ca}^{2+}\right]_{i}$ in a linear manner, changes in $\left[\mathrm{Ca}^{2+}\right]_{i}$ will not necessarily be exactly matched by changes in augmentation if the change in $\left[\mathrm{Ca}^{2+}\right]$ is not the rate-limiting step. This would occur if the forward or reverse rates of the biochemical events driven by $\mathrm{Ca}^{2+}$ and responsible for augmentation are slower than the buildup or recovery or $\mathrm{Ca}^{2}$. For example, immediately after the offset of high-frequency trains that raise $\left[\mathrm{Ca}^{2+}\right]_{i}$ to levels of $1.5 \mu \mathrm{M}$ or greater, the recovery rate of $\left[\mathrm{Ca}^{2+}\right]_{i}$ initially has a time constant of less than $1 \mathrm{sec}$ in crayfish nerve terminals that have little ( $<200 \mu \mathrm{M}$ fura-2) exogenous calcium buffer (Tank et al., 1994). Augmentation would appear to have a higher order of dependence on $\left[\mathrm{Ca}^{2+}\right]_{i}$ during this time if the reverse rate of the augmentation process is slow relative to the rate $\Delta\left[\mathrm{Ca}^{2+}\right]_{i}$. Similarly, at the start of a train, when the residual $\left[\mathrm{Ca}^{2+}\right]_{i}$ is low, the buildup of synaptic enhancement driven by residual $\mathrm{Ca}^{2+}$ may lag behind the $\left[\mathrm{Ca}^{2+}\right]$ buildup. Evidence for temporal dissociation between $\left[\mathrm{Ca}^{2+}\right]_{i}$ and an augmentation-like enhancement has been obtained at the mossy fiber-CA3 synapse of mammalian hippocampus (Regehr et al., 1994). Besides the time required for biochemical reactions such as phosphorylation, other more "physical" events associated with vesicle mobilization might also contribute to a lag in the response of the system to rapid changes in $\left[\mathrm{Ca}^{2+}\right]_{i}$ (Lin and Llinás, 1993). The conditions of our experiments were not optimized to explore the temporal dynamics of the relationship between $\Delta\left[\mathrm{Ca}^{2+}\right]_{i}$ and augmentation. In fact, by slowing the rate of $\left[\mathrm{Ca}^{2+}\right]_{i}$ recovery after trains with exogenous buffer, in many experiments we set up conditions where it was less likely that reverse biochemical reactions would be unable to keep pace with declining $\left[\mathrm{Ca}^{2+}\right]_{i}$ after trains.

If either of $\mathrm{F} 1$ or $\mathrm{F} 2$ is dependent upon $\mathrm{Ca}^{2+}$, then the failure of moderatc maintaincd $\left[\mathrm{Ca}^{2+}\right]$ increases during or after trains to stimulate these processes significantly is consistent with their having relatively low affinities for $\mathrm{Ca}^{2+}$. This may be relevant to our observation that when $\mathrm{Ca}^{2+}$ levels were raised to very high levels, $>2 \mu \mathrm{M}$, we found a qualitatively different relationship between enhancement and $\left[\mathrm{Ca}^{2+}\right]_{i}$ than that seen during and after trains. Although the physiological relationship between evoked release and spontaneous transmitter release is unclear, our observation that mejp frequency (and to a less well characterized extent, ejp enhancement) is nonlinearly related to $\left[\mathrm{Ca}^{2+}\right]_{i}$ when $\left[\mathrm{Ca}^{2+}\right]_{i}$ is elevated above $1 \mu \mathrm{M}$, is consistent with expression of additional, lower-affinity $\mathrm{Ca}^{2+}$-sensitive processes, on top of the high-affinity augmentation process. We suggest this may reflect activation of processes that normally are responsible for $F 1$ or $F 2$. However, spatiotemporally averaged $\left[\mathrm{Ca}^{2+}\right]_{i}$ approaches $3 \mu \mathrm{M}$ during $33 \mathrm{~Hz}$ trains, yet there is still 
apparently a linear relationship between $\Delta\left[\mathrm{Ca}^{2+}\right]_{i}$ and a component of synaptic enhancement (Delaney et al., 1989, their Fig. 2 ). This apparently contradicts the nonlinear relationship between mejps and $\left[\mathrm{Ca}^{2+}\right]_{i}$ in Figure 8 . This observation is understandable if we assume that normally the $\mathrm{Ca}^{2+}$ transients associated with the action potentials in the high-frequency train fully activate the $F 1 / F 2$ mechanism. In this scenario during high-frequency trains $\mathrm{Fl} / \mathrm{F} 2$ facilitatory sites (near the $\mathrm{Ca}^{2+}$ channels) are "saturated" before the spatially averaged $\left[\mathrm{Ca}^{2+}\right]_{i}$ measured by fura- 2 reaches even $1 \mu \mathrm{M}$. This leaves only the augmentation/ptp process (located at a distance from the $\mathrm{Ca}^{2+}$ channels) to be modulated in a linear fashion by residual $\mathrm{Ca}^{2+}$. On the other hand, during sustained increases in $\left[\mathrm{Ca}^{2+}\right]_{i}$, in the absence of high $\left[\mathrm{Ca}^{2+}\right]$ transients from action potentials, effects of $F 1$ and $F 2$ are significantly combined with those of augmentation only as $\left[\mathrm{Ca}^{2+}\right]_{i}$ increases into the micromolar range. Alternatively, it may be that it is inappropriate to compare modulation of mejp frequency with modulation of evoked transmitter release.

There are many pharmacologically and kinetically defined types of $\mathrm{Ca}^{2+}$ channels, several of which have been found in nerve terminals. The low [Ca] required for augmentation does not require colocalization of $\mathrm{Ca}$ channels with the molecules responsible for augmentation. A possible role for $\mathrm{Ca}^{2+}$ channels other than those that are colocalized with docked vesicles, that is, "release channels," is apparent within the context of the spatiotemporal framework we are presenting. Two species of channels might be expected at some presynaptic terminals: "release channels," located close to docked vesicles, and "augmenting" channels, which could be more diffusely distributed. Thus, the effects of various $\mathrm{Ca}^{2+}$ channel blockers on release as well as activity-dependent enhancement of release need to be examined, particularly at synapses such as those made by peptide-releasing terminals that often appear to require bursts of action potentials to release significant amounts of transmitter and therefore may require increased basal $\left[\mathrm{Ca}^{2+}\right]_{i}$ for normal operation. An obvious result of having two separate species of channels in presynaptic terminals would be that modulation of residual $\mathrm{Ca}^{2+}$ and thus augmented release could be achieved separate from nonaugmented release. Modulation of $\mathrm{Ca}^{2+}$-pumps either through neurotransmitters or genetic control of isozyme synthesis is another way in which synaptic enhancement could be controlled by varying the rate of activity-related buildup and recovery of $\left[\mathrm{Ca}^{2+}\right]_{i}$.

In summary, in the spatiokinetic framework, $\mathrm{Ca}^{2+}$-mediated enzyme systems can be "separated" by large differences in forward kinetics or $\mathrm{Ca}^{2+}$ affinity in addition to their microdistribution relative to open $\mathrm{Ca}^{2+}$ channels. This can in principle obviate the need to invoke a high-order dependence of evoked release on $\left[\mathrm{Ca}^{2+}\right]_{i}$, in order to account for the unchanging time course of release or the small activation of spontaneous release in the presence of various facilitation processes, as is the case in traditional residual $\mathrm{Ca}^{2+}$ models (Katz, 1968; Zucker, 1974a,b; Zucker and Lara-Estralla, 1983; Cohen and Van der Kloot, 1985).

The spatiokinetic model of enhancement: an analog chemical computation

Nervous system computation is often perccived in tcrms of electrical events: action potentials, synaptic potentials, and so on. The buildup and recovery of $\mathrm{Ca}^{2+}$ ions in presynaptic terminals that we have measured and the way this produces synaptic enhancement can be considered a simple form of chemical, rather than electrical, computation. The buildup of $\mathrm{Ca}^{2+}$ implements the dynamic function of integration. The recovery is a simple form of memory. This manipulation of information may not have a visible correlate in the cell electrical activity; it may be a strictly chemical process and electrically silent. The spatiokinetic framework envisaged in Table 2 is a summary of the rich and complex chemical dynamics that is possible in small, micrometer-sized structures. The system of biochemical reactions is perhaps best considered as an analog computer. It is perhaps one example of the possibly rich set of chemical processes that neurons use to produce the dynamic functions that are the building blocks of biological computation.

\section{References}

Adler EM, Augustine GJ, Duffy SN, Charlton MP (1991) Alien intracellular calcium chelators attenuate neurotransmitter release at the squid giant synapse. J Neurosci 11:1496-1507.

Atwood HL, Wojtowicz JM (1986) Short-term and long-term plasticity and physiological differentiation of crustacean motor synapses. Int Rev Neurobiol 28:275-360.

Atwood HL, Dixon D, Wojtowicz JM (1989) Rapid introduction of long-lasting synaptic changes at crustacean nmjs. J Neurobiol 20:373385.

Augustine GJ, Charlton MP, Smith SJ (1987) Calcium action in synaptic transmitter release. Annu Rev Neurosci 10:633-693.

Augustine GJ, Adler EM, Charlton MP (1991) The calcium signal for transmitter secretion from presynaptic nerve terminals. Ann NY Acad Sci 635:365-381.

Balnave RJ, Gage PW (1974) On facilitation of transmitter release at the toad neuromuscular junction. J Physiol (Lond) 239:657-675.

Baylor SM, Hollingsworth S (1988) Fura-2 calcium transients in frog skeletal muscle fibres. J Physiol (Lond) 403:151-192.

Bittner GD, Baxter DA (1991) Synaptic plasticity at crayfish neuromuscular junctions-facilitation and augmentation. Synapse 7:235243.

Bittner GD, Segundo JP (1989) Effects of stimulus timing on transmitter release and postsynaptic membrane potential at crayfish neuromuscular junctions. J Comp Physiol [A] 165:371-382.

Charlton MP, $\Lambda$ twood HL (1977) Modulation of transmitter release by intracellular sodium in squid giant synapse. Brain Res 134:367371.

Charlton MP, Smith SJ, Zucker RS (1982) Role of presynaptic calcium ions in synaptic facilitation and depression at the squid giant synapse. J Physiol (Lond) 323:173-193.

Cohen IR, Van der Kloot W (1985) Calcium and transmitter release. Int Rev Neurobiol 27:299-336.

Connor J, Kretz R, Kandel E (1986) Calcium levels measured in a presynaptic neurone of Aplysia under conditions that modulate transmitter release. J Physiol (Lond) 375:625-642.

Delaney KR, Tank DW (1991) Calcium-dependent and calcium-independent enhancement of transmitter release at the crayfish neuromuscular junction studied with fura- 2 imaging. Ann NY Acad Sci 635:452-454.

Delaney KR, Zucker RS (1990) Calcium released by photolysis of DM-nitrophen stimulates transmitter release at squid giant synapse. J Physiol (Lond) 426:473-498.

Delaney KR, Zucker RS, Tank DW (1989) Calcium in motor nerve terminals associated with posttetanic potentiation. J Neurosci 9:35583567.

Delaney KR, Llinás RR, Tank DW (1990) A component of facilitation at crayfish neuromuscular junction is linearly related to cytoplasmic calcium. Soc Neurosci Abstr 16.

Delaney KR, Tank DW, Zucker RS (1991) Presynaptic calcium and serotonin-mediated enhancement of transmitter release at crayfish neuromuscular junction. J Neurosci 12:2631-2643.

Dixon D, Atwood HL (1985) Crayfish motor nerve terminal's response to serotonin examined by intracellular microelectrode. J Neurobiol $16: 409-432$.

Dudel J (1981) The effect of reduced calcium on quantal unit current and release at the crayfish neuromuscular junction. Pfluegers Arch 391:35-40.

Dudel J (1988) Modulation of quantal synaptic release by serotonin 
and forskolin in crayfish motor nerve terminals. In: NATO ASI series, Vol H19, Modulation of synaptic transmission and plasticity in nervous systems (Hertting G, Spatz H-C, eds). Berlin: Springer.

Erulkar SD, Rahamimoff R (1978) The role of calcium ions in tetanic and post-tetanic increase of miniature end-plate potential frequency. J Physiol (Lond) 278:501-511.

Fogelson AL, Zucker RS (1985) Presynaptic calcium diffusion from various arrays of single channels-implications for transmitter release and synaptic facilitation. Biophys J 48:1003-1017.

Grynkiewicz G, Poenie M, Tsien RY (1985) A new generation of $\mathrm{Ca}^{2+}$ indicators with greatly improved fluorescence properties. J Biol Chem $260: 3440-3450$.

Harrison SM, Bers DM (1987) The effect of temperature and ionic strength on the apparent Ca-affinity of EGTA and the analogous $\mathrm{Ca}$ chelators BAPTA and dibromo-BAPTA. Biochim Biophys Acta 925: 133-143.

Hochner B, Parnas H, Parnas I (1989) Membrane depolarization evokes neurotransmitter release in the absence of calcium entry. Nature 342: 433-435.

Kao JP, Tsien RY (1988) Calcium binding kinetics of fura-2 and azo-1 from temperature-jump relaxation measurements. Biophys J 53:635639.

Katz B, Miledi R (1968) The role of calcium in neuromuscular facilitation. J Physiol (Lond) 195:481-492.

Lin J-W, Llinás RR (1993) Depolarization-activated potentiation of T fiber synapse in the blue crab. J Gen Physiol 101:45-65.

Linder TM (1974) The accumulative properties of facilitation at crayfish neuromuscular synapses. J Physiol (Lond) 238:223-234.

Llinás RR, McGuiness TL, Leonard CS, Sugimòri M, Greengard P (1985) Intraterminal injection of synapsin I or calcium calmodulindependent protein kinase II alters neurotransmitter release at the squid giant synapse. Proc Natl Acad Sci USA 82:3035-3039.

Llinás RR, Sugimori M, Walton K (1987) Further studies on depolarization release coupling at squid giant synapse. Adv Exp Med Biol 221:1-17.

Llinás RR, Sugimori M, Silver RB (1992) Microdomains of high calcium concentration in a presynaptic terminal. Science 256:677679.

Magleby K (1987) Short-term changes in synaptic efficacy. In: Synaptic function (Edelman GM, Gall LE, Maxwell W, Cowan WM, eds), pp 21-56. New York: Wiley.

Miledi R (1973) Transmitter release induced by injection of calcium ions into nerve terminals. Proc R Soc Lond [Biol] 212:197-211.

Miledi R, Parker I (1981) Calcium transients recorded with arsenazo III in the presynaptic terminal of the squid giant synapse. Proc R Soc Lond [Biol] 212:197-211.

Minta A, Tsien RY (1989) Fluorescent indicators for cytosolic sodium. J Biol Chem 264:19449-19457.

Mulkey RM, Zucker RS (1991) Action potentials must admit calcium to evoke transmitter release. Nature 350:153-155.

Mulkey RM, Zucker RS (1992) Posttetanic potentiation at the crayfish neuromuscular junction is dependent on both intracellular calcium and sodium ion accumulation. J Neurosci 12:4327-4336.

Regehr WG, Tank DW (1991) The maintenance of LTP at hippocampal mossy fiber synapses is independent of sustained presynaptic calcium. Neuron 7:451-459.

Regehr WG, Tank DW (1992) Calcium concentration dynamics pro- duced by synaptic activation of CA1 hippocampal pyramidal cells. $J$ Neurosci 12:4202-4223.

Regehr WG, Delaney KR, Tank DW (1994) The role of presynaptic calcium in short-term enhancement at the hippocampal mossy fiber synapse. J Neurosci 14:523-537.

Roberts WM, Jacobs RA, Hudspeth AJ (1990) Localization of ion channels involved in frequency selectivity and synaptic transmission at presynaptic active zones of hair cells. J Neurosci 10:3664-3684.

Simon S, Llinás RR (1985) Compartmentalization of the submembrane calcium activity during calcium influx and its significance in transmitter release. Biophys J 48:485-498.

Sivaramakrishnan S, Bittner GD, Brodwick MS (1991) Presynaptic facilitation at the crayfish neuromuscular junction: role of calciumactivated potassium conductance. J Gen Physiol 98:1181-1196.

Smith SI, Zucker RS (1980) Aequorin facilitation and intracellular calcium accumulation in mollusc neurons. J Physiol (Lond) 300:167196.

Stanley E (1986) Decline in calcium cooperativity as the basis of facilitation at the squid giant synapse. J Neurosci 6:782-789.

Swandulla D, Hans M, Zipser K, Augustine G (1991) Role of residual calcium in synaptic depression and posttetanic potentiation: fast and slow calcium signaling in nerve terminals. Neuron 7:915-926.

Tank DW, Delaney KR, Regehr WG (1994) A quantitative analysis of presynaptic calcium dynamics that contribute to short-term enhancement of transmitter release. J Neurosci, in press.

Wojtowicz JM, Atwood HL (1984) Presynaptic membrane potential and transmitter release at the crayfish neuromuscular junction. J Neurophysiol 52:99-113.

Wojtowicz JM, Atwood HL (1986) Long-term facilitation alters transmitter releasing properties at the crayfish neuromuscular junction. $\mathbf{J}$ Neurophysiol 54:220-230.

Wojtowicz JM, Atwood HL (1988) Presynaptic long-term facilitation at the crayfish neuromuscular junction: voltage-dependent and iondependent phases. J Neurosci 8:4667-4674.

Yamada WM, Zucker RS (1992) Time course of transmitter release calculated from simulations of a calcium diffusion model. J Biophysiol 61:671-682.

Zengel J, Magleby K, Horn J, McAfee D, Yarowsky P (1980) Facilitation, augmentation and potentiation of synaptic transmission at the superior cervical ganglion of the rabbit. J Gen Physiol 76:213-231.

Zucker RS (1974a) Crayfish neuromuscular facilitation activated by constant presynaptic action potentials and depolarizing pulses. J Physiol (Lond) 241:69-80.

Zucker RS (1974b) Characteristics of crayfish neuromuscular facilitation and their calcium dependence. J Physiol (Lond) 241:91-110.

Zucker RS (1989) Short-term synaptic plasticity. Annu Rev Neurosci 12:13-31.

Zucker RS, Fogelson AL (1986) Relationship between transmitter release and presynaptic calcium influx when calcium enters through discrete channels. Proc Natl Acad Sci USA 83:3032-3036.

Zucker RS, Lara-Estrella LO (1983) Post-tetanic decay of evoked and spontaneous transmitter release and a residual-calcium model of synaptic facilitation at crayfish neuromuscular junctions. J Gen Physiol 81:355-372.

Zucker RS, Delaney KR, Mulkey RM, Tank DW (1991) Presynaptic calcium in transmitter release and posttetanic potentiation. Ann NY Acad Sci 635:191-207. 